Portland State University

PDXScholar

\title{
Intergenerational Programming: A Confluence of Interests Between the Frail Elderly and Urban Youth
}

Doris Schindler

Portland State University

Follow this and additional works at: https://pdxscholar.library.pdx.edu/open_access_etds Let us know how access to this document benefits you.

\section{Recommended Citation}

Schindler, Doris, "Intergenerational Programming: A Confluence of Interests Between the Frail Elderly and Urban Youth" (1992). Dissertations and Theses. Paper 1387.

https://doi.org/10.15760/etd.1386

This Dissertation is brought to you for free and open access. It has been accepted for inclusion in Dissertations and Theses by an authorized administrator of PDXScholar. Please contact us if we can make this document more accessible: pdxscholar@pdx.edu. 
INTERGENERATIONAL PROGRAMMING: A CONFLUENCE OF

INTERESTS BETWEEN THE FRAIL ELDERLY AND URBAN YOUTH

\author{
by \\ DORIS SCHINDLER
}

A dissertation submitted in partial fulfillment of the

requirements for the degree of

DOCTOR OF PHILOSOPHY

in

URBAN STUDIES

Portland State University

(c) 1992 


\section{TO THE OFFICE OF GRADUATE STUDIES:}

The members of the Committee approve the thesis of Doris Schindler presented June 26, 1992.

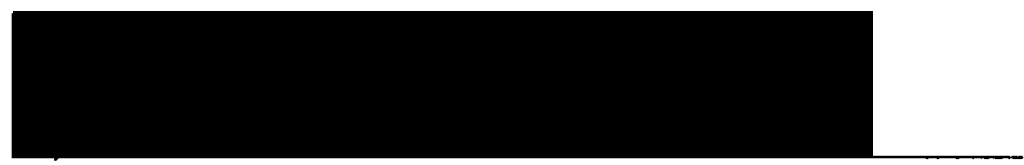

Gerald F. Blake, Chair

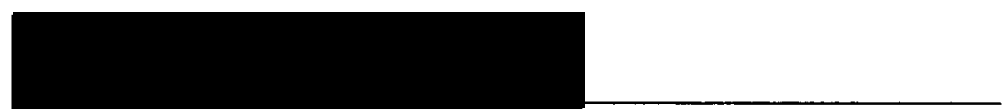

Leonard D. Cain

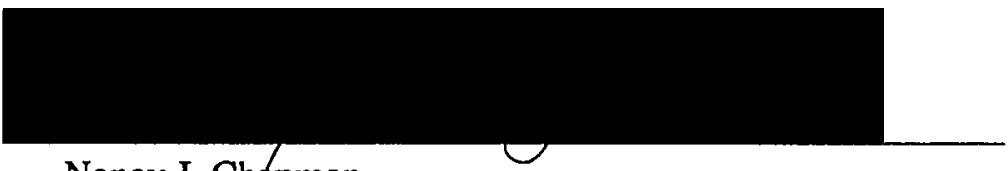

Nancy J. Chápman
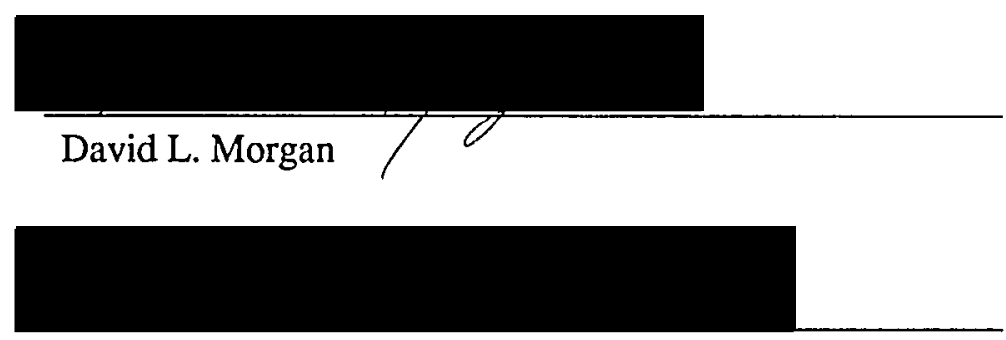

Maria Talbott

APPROVED:

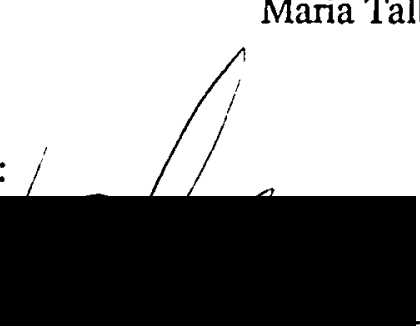

Nohad Toulan, Dean, School of Urban and Public Affairs

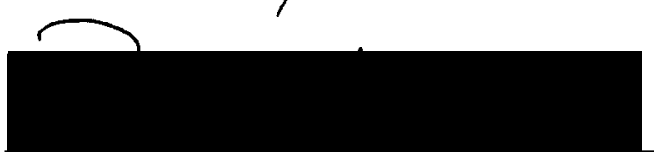

Roy W. Koch, Vice Provost for Graduate Studies and Research 


\section{ACKNOWLEDGMENTS}

This dissertation is the result of the help and assistance given to me during the course of its preparation. It was my pleasure to work closely with my dissertation committee chairman, Dr. Gerald F. Blake. His energy and enthusiasm were essential in keeping the process moving forward. My thanks to Drs. Nancy Chapman, Leonard Cain, David Morgan, and Maria Talbott for their continued support and encouragement.

The staff of Friendly House gave freely of time and interest in Project MAIN. The participating youth were given the experience of working with adults in meaningful work. Last, but not least, I want to thank my family for the gifts of time and space in which to complete this study. 


\section{TABLE OF CONTENTS}

PAGE

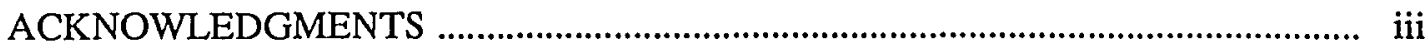

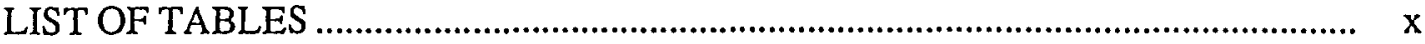

\section{CHAPTER}

I INTRODUCTION ..................................................................................... 1

Statement of the Problem ................................................................ 1

Research Questions ............................................................................. 2

The Frail Elderly ........................................................................ 2

Demographic Changes .............................................................. 2

Independence and Autonomy ................................................... 3

Social Isolation ....................................................................... 4

Age Segregation ....................................................................... 4

Needs and Goals ............................................................................ 4

Summary .............................................................................. 5

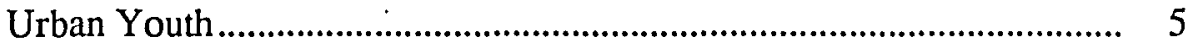

School Dropouts .......................................................................... 5

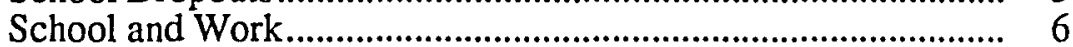

Youth Employment During High School....................................... 6

Changing Demand of the Job Market ........................................ 6

Needs and Goals.......................................................................... 7

Summary ................................................................................. 7

Intergenerational Programming ....................................................... 7

Summary ....................................................................... 8

Overview of the Following Chapters …............................................ 9

II REVIEW OF LITERATURE ................................................................ 10

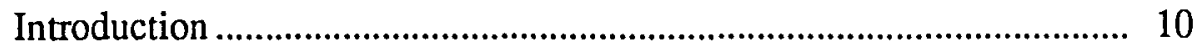


The Frail Elderly $v$

The Frail Elderly .................................................................................. 10

Demographic Trends ................................................................. 10

Long-Term Care ...................................................................... 11

Goals of Long-Term Care ........................................................ 13

Level of Independence ........................................................... 13

Tasks of Daily Living ............................................................ 14

Summary ...................................................................................... 17

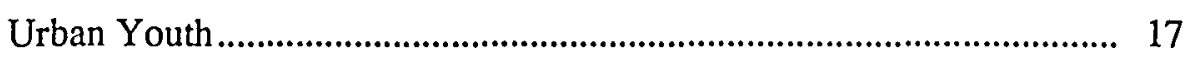

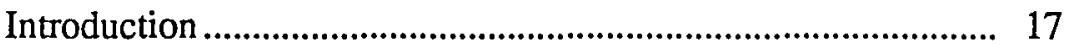

Youth in Transition ................................................................... 18

Goals of Urban Youth .............................................................. 18

Effect of Working on Education ................................................... 19

Quality of the Work Experience ............................................... 21

Disadvantages ........................................................................ 21

Long- and Short-Term Advantages............................................ 22

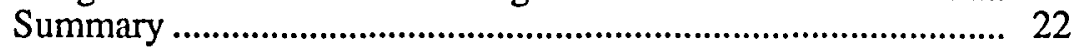

Intergenerational Programming .................................................... 22

Introduction .............................................................................. 22

Theoretical Rationale for Intergenerational Programming ......... 23

Models of Intergenerational Programs ......................................... 23

Reciprocity in Intergenerational Programs ................................ 24

Intergenerational Programming .............................................. 24

Goals of Intergenerational Programs ....................................... 25

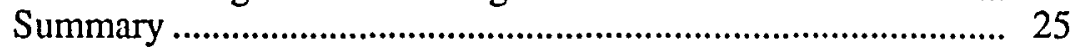

III INTERGENERATIONAL PROGRAMS ................................................. 27

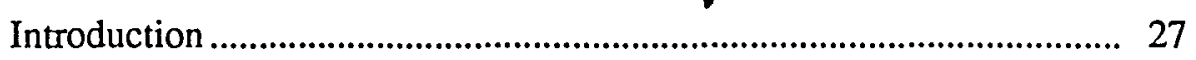

Characteristics of Intergenerational Programs ................................... 27

A Clearly Defined Need for the Program ................................ 27

Resources ................................................................................... 28

Planning and Goals ............................................................... 28

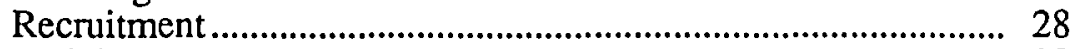

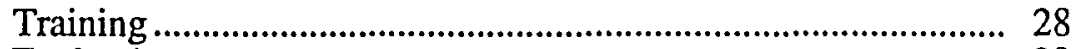

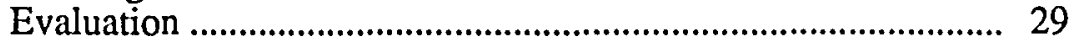

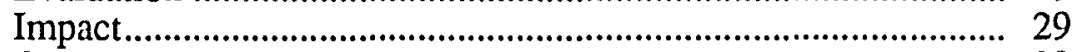

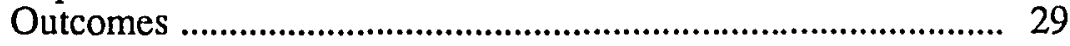

Selected Intergenerational Programs ................................................ 29

Youth in Service to Elders (Pittsburgh, PA) .............................. 29

The Intergenerational Linkages Program $($ Ann Arbor, MI;

Chicago, IL; Atlanta, GA) .................................................... 31

Elderly-Youth Exchange (EYE) (Portland, OR) ......................... 33

Summary ................................................................................. 36 
Intergenerational Programs that Encountered Problems...................... 36

Introduction ....................................................................... 36

Camp Fire's Intergenerational Program Delivery System

(Kansas City, MO) ................................................................. 36

Problems Encountered .................................................................. 37

Channel One: Senior Citizens' Food Co-Op

(Rochester, MN) ................................................................... 38

Summary of the Five Programs ............................................... 39

Factors Relevant to all Five Programs ...................................... 40

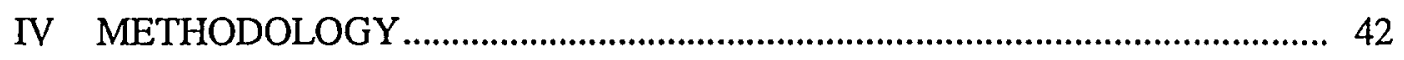

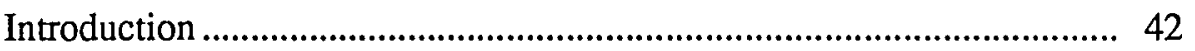

Location .......................................................................... 42

The Elderly ............................................................................ 42

The Participating Youth ......................................................... 42

Design of the Study .......................................................................... 43

Case Study......................................................................... 43

Goals of the Project....................................................................... 43

Establishing the Need for Project MAIN ............................................ 44

The Elderly: Special Problems Related to Shopping ................ 44

Problems of Youth in an Urban Area........................................... 44

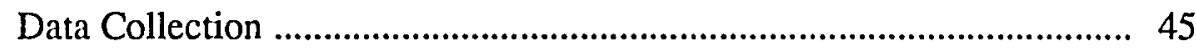

Survey of 50 Frail Elderly Clients ........................................ 45

Youth, Elderly Clients, and Other People .................................. 45

Staff Meetings ........................................................................... 45

Reports to Portland Youth Advocates............................................ 46

Presentation of Data ................................................................... 46

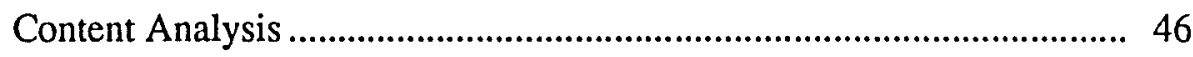

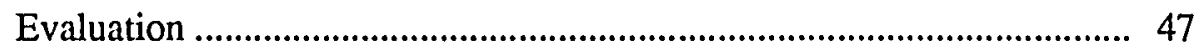

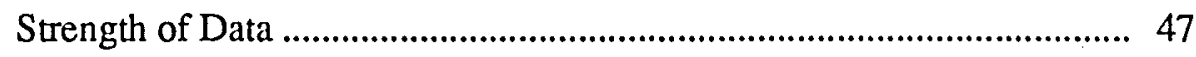

Weaknesses of Data ..........................................................................4 47

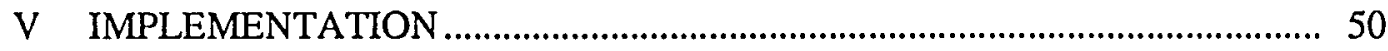

Pilot Phase of Project MAIN: Summer, 1983 ..................................... 50

Introduction .......................................................................... 50

Beginning the Pilot Project ......................................................... 50 


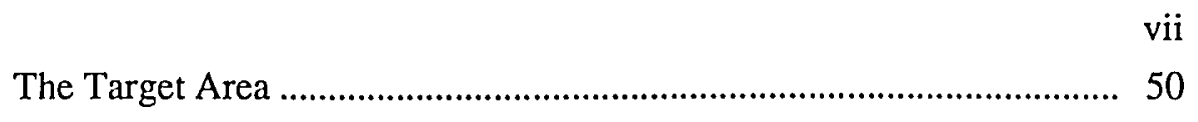

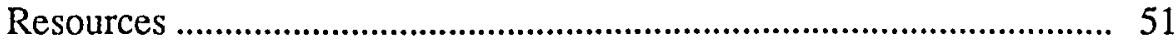

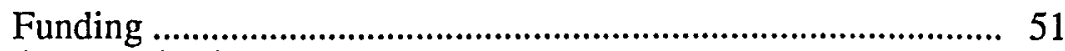

Community Support ............................................................... 51

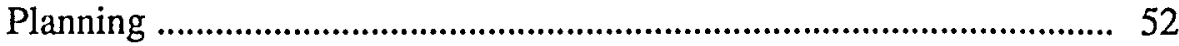

Project Oriented Learning: The First Element .......................... 52

Active Youth Participation: The Second Element ..................... 52

Inter-Age Contact: The Third Element ...................................... 53

Establishment of New Organizational Linkages: The

Fourth Element......................................................................... 53

Quality of the Project MAIN Experience .................................... 53

Goals of Project MAIN ................................................................... 53

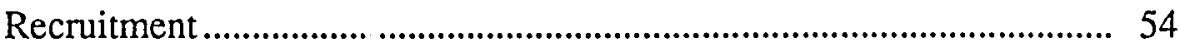

Youth: Shopping Assistants .................................................. 54

Elderly Clients..................................................................... 55

Training the Mobile Assistants ............................................................ 55

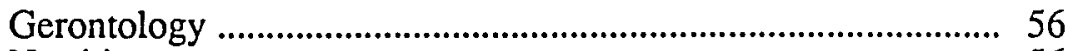

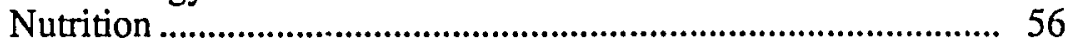

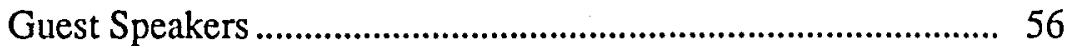

Communication ........................................................................... 57

Clear the Air ......................................................................... 57

Hands-On Training ................................................................ 57

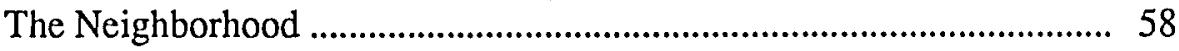

The Shopping Service ....................................................................... 59

Introduction to Clients ............................................................ 59

The Elderly Clients ............................................................... 59

Evaluation of the Shopping Service by the Elderly Clients

of the Pilot Project................................................................................ 60

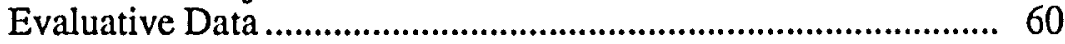

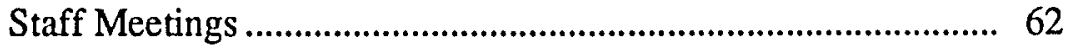

VI DEMONSTRATION PROJECT: FALL 1983 - WINTER 1987 ..................... 64

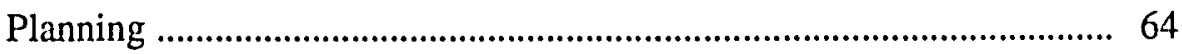

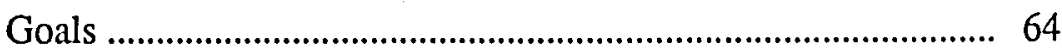




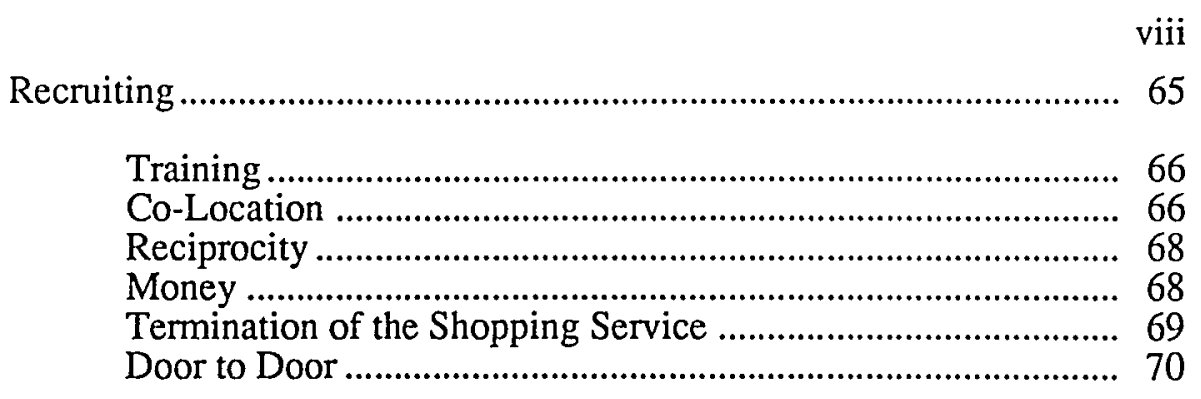

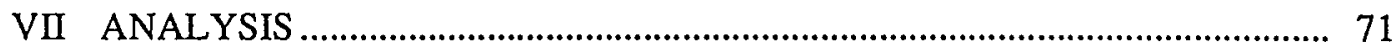

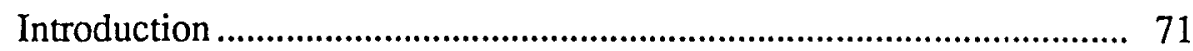

Evaluations of and by Mobile Assistants ......................................... 72

Survey of Elderly or Disabled Clients .................................. 72

Summary .............................................................................. 74

Comparison between Initial Expectations and Later

Experiences .............................................................................. 74

Community Evaluation ............................................................ 75

Senior Service Center............................................................... 75

High School ......................................................................... 76

Reports to Portland Youth Advocates......................................... 78

Staff Meetings .............................................................................. 81

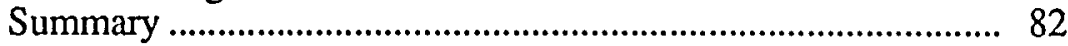

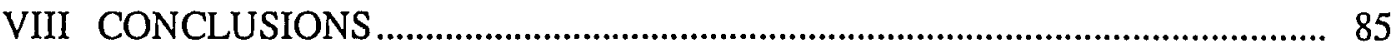

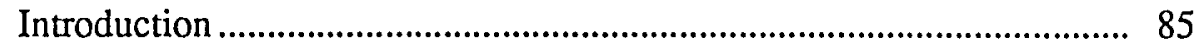

Impact of Project MAIN ....................................................... 87

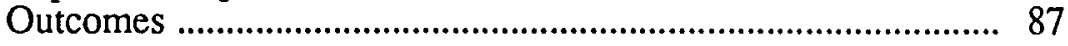

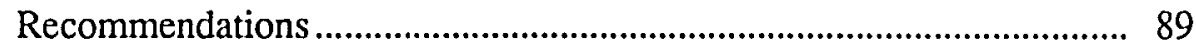

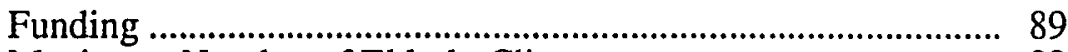

Maximum Number of Elderly Clients .................................... 89

Training of Youth...................................................................... 89

Mandatory Continuing Training .............................................. 90

Youth Participating in Instruction ............................................. 90

Supervision of Shopping Service ............................................ 90

Recruitment of Youth.................................................................... 91

Replication of the Project........................................................... 92

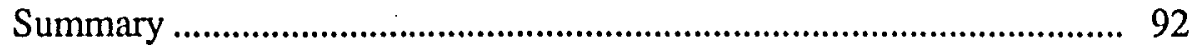

Evaluating Project MAIN by the Matrix.................................. 93

What Would Work .......................................................................... 93

What can be Learned from Project MAIN .................................. 94

Need to Maintain and Increase a Sensitivity to the Elderly ........ 94 


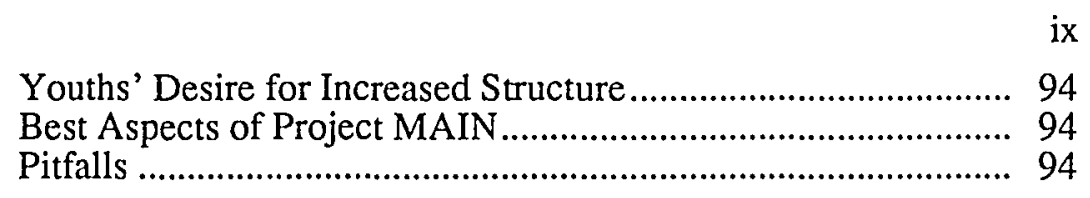

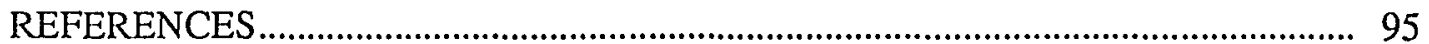

APPENDICES

A GUIDED INTERVIEW: PORTLAND AREA YOUTH ............................... 100

B EXCERPTS FROM PROJECT MAIN WEEKLY STAFF

MEETINGS: $1984-1987$............................................................................. 102

C CERTIFICATION OF ACTION LEARNING CREDIT ............................... 106

D APPLICATION FOR EMPLOYMENT …………….................................. 108

E PROJECT MAIN 1985: ASSESSMENT BY CLIENTS …........................... 110

F PROJECT MAIN SURVEY: RESPONSES OF CLIENTS (N=50) ........... 113 


\section{LIST OF TABLES}

TABLE

PAGE

I U.S. Population from 65 Years of Age and Older: Number and Percent of Total U.S. Population for Selected Years

II Distribution of Functional Disability by Age $65+$ of U.S. NonInstitutionalized Population in 1977

III Continuum of Long-Term Services by Level of Independence.

IV Possible Health and Social Services Interventions by Level of Independence

V Type of Job Held by Students Currently Employed, by Grade: Spring 1980 , by Percent.

VI Percentage Distributions of Hours Worked per Week of Students

Currently Employed, by Sex: Spring 1980

VII Factors in Intergenerational Programs.

VIII Project MAIN Survey : 1985-86 Frequency Distribution of Age by Sex

IX Project MAIN: What Youth Initially Expected and Later Experienced $(n=16)$

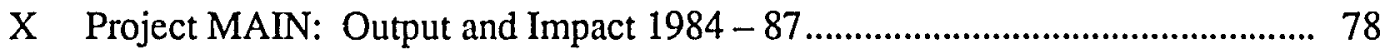

XI Average Number of Trips per Shopper per Month .......................................... 79

XII Average Hours Worked by Shoppers Each Month .......................................... 79

XIII Average Hours Worked by Coordinators Each Month ........................................ 79

XIV Average Time per Shopping Trip ......................................................... 80

XV Frequency of Excerpts Relating to Clients, Youth, Community, and Project MAIN 
AN ABSTRACT OF THE DISSERTATION OF Doris Schindler for the Doctor of

Philosophy in Urban Studies and Planning presented June 26, 1992.

Title: Intergenerational Programming: A Confluence of Interests Between the Frail Elderly and Urban Youth.

APPROVED BY THE MEMBERS OF THE DISSERTATION COMMITTEE:

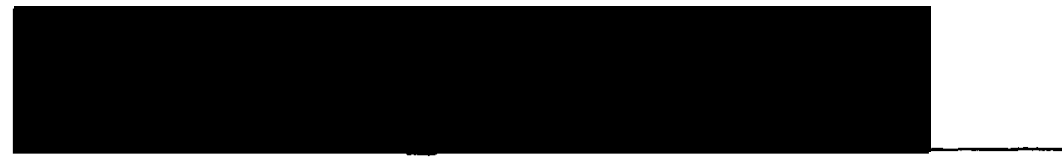

Gerald F. Blake, Chair

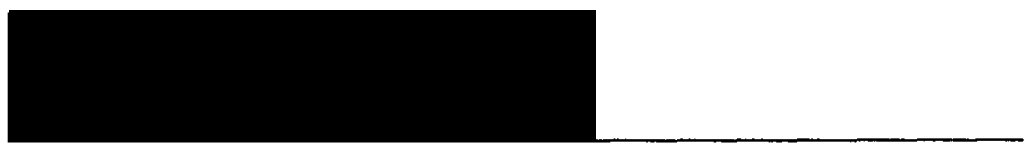

Leonard D. Cain

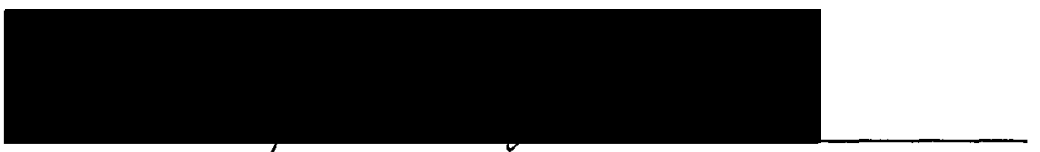

Nancy J. Chapman

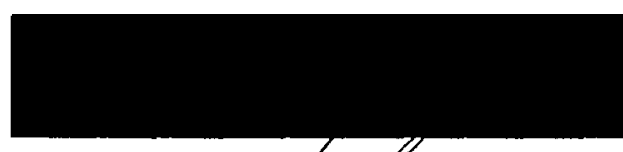

David L. Morgan

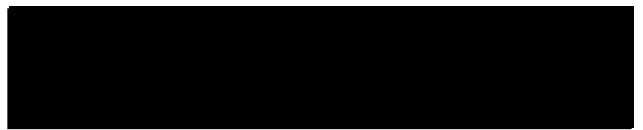

Maria Talbott

Two groups of urban residents present ongoing problems, the frail elderly, and disadvantaged youth who are approaching transition from school to the work force. Many of the disadvantaged youth are at risk because of family background, inadequate 
education, and lack of work experience. Many of the frail elderly are unable to care for themselves because of debility, chronic illness, or functional impairments (Eustis, 1974).

The United States is experiencing an unprecedented increase in the numbers of persons over 65 years of age and it is expected that between 1980 and 2000 there will be a 67 percent increase in persons 80 and over. These demographic changes are significant especially for long-term care policy for the elderly. There is an urgent need to provide the kind of care that permits them to continue to live in their own homes. The frail elderly perceive their need for a dependable source of food as a primary requirement. If this is not met, institutional care becomes the only possible option.

Urban youth face an increasing pressure to take a job in order to earn money, often at the expense of further education. Part-time work and school can be managed, and with planning, the classroom curriculum can be blended with the job.

Intergenerational programs present a possible solution to some of the problems of the frail elderly and youth. They can be brought together through one of these programs for their mutual benefit.

Intergenerational programming is the process of planned and purposeful interaction between generations. The programs encompass a range of ideas as they are guided by the needs of the community and its resources to meet these needs (Newman, 1983). Project MAIN was one of these projects.

In 1983 under the auspices of Portland Youth Adwocates, Project MAIN was created to meet the needs of the frail elderly and youth in an urban area. Many of the frail elderly were confined to their homes, unable to do ordinary tasks such as grocery shopping. Low-income teenagers needed access to an income-generating jobs program that would permit them to remain in school. Project MAIN was planned to help disadvantaged youth and simultaneously enrich the lives of the elderly (Ventura-Merkel, 1988). 
Project MAIN was conceived as a dynamic entity that could not be seen directly, but perceived as a process that had qualitative effects on those with whom it came in contact. It was planned as an active participatory learning experience for youth. Relevant classroom curricula blended with part-time jobs. The focus was on full participation by the youth in the process of providing a shopping service for the homebound elderly.

Two important elements of the project were active youth participation and project-oriented learning. The youth planned and operated a shopping service for the frail elderly clients. The youth continued with their education and worked part-time. They began with minimum wage and increases came regularly, following satisfactory evaluation by peers and staff. As they became more competent, they assisted the staff with supervision and instruction.

A case study explored the outcomes of Project MAIN. A weakness in the data from guided interviews of the clients resulted from memory loss and confusion encountered in a few of the elderly. A strength was the flexible interviews which gave the elderly time to explore new ideas as they emerged. The outcomes of Project MAIN were measured by the level of satisfaction for both the elderly clients and the participating youth. The leveis of satisfaction were high in the pilot project, with its four weeks of intensive training and careful supervision. Adequate funding from private organizations made this possible. In the demonstration phase, funding became an acute problem. Training and supervision of the youthful shoppers was curtailed. Although the clients found the service better than they had before Project MAIN, complaints of broken appointments and declining dependability began to be heard.

It became evident that the youth were in need of better preparation and more intensive supervision. Because of lack of funds, it was not possible to supply staff for these tasks. 
From the outcomes of the pilot project, it is evident that the concept of Project MAIN is a viable one for meeting the needs of the frail elderly and youth. However, from the demonstration phase, it was seen that without adequate funding, they quality of the shopping service declined. Decisions need to be made in the early planning of a program like Project MAIN. Elimination of staff needed for training and supervision in favor if increasing the number of youthful shoppers can threaten the viability of the program. 


\section{CHAPTER I}

\section{INTRODUCTION}

There are two groups of urban residents who, although quite unlike each other, can complement each others' needs. They are the frail elderly and low-income teenagers.

Many of the frail elderly are physically confined to their homes, unable to do ordinary errands, because of their debility, chronic illness, or other functional impairments (Eustis, 1984). Many low-income teenagers may be at risk because of family backgrounds and inadequate education (Ford Foundation Letter, 1989).

The frail elderly need help with grocery shopping, and low-income teenagers need an income-generating jobs program so that they may earn some money. The matching of needs in Project Main was an attempt to coordinate disparate community demographics in a mutually beneficial way.

\section{STATEMENT OF THE PROBLEM}

1. The frail elderly, especially those who live alone, have a special need related to shopping for food. If this need is not met, institutional care may be the only alternative.

2. Urban youth face problems when they are approaching transition from school to work. Many drop out of school before they have acquired skills necessary for successful employment. They are unprepared for the labor market and their future is in jeopardy (Galvin and Newman, 1984). 
3. Intergenerational programs are purposeful interactions between generations, designed to bring youth and elderly together for their mutual benefit and in response to their unique needs (Newman, 1983).

\section{RESEARCH QUESTIONS}

The research questions concentrate on the needs of the frail elderly and those of urban youth. Analysis of intergenerational programs will identify variables that facilitate or detract from the success of existing or proposed programs. The focus will be on Project MAIN (Mobile Assistants in Nutrition), an intergenerational program that was in operation in Portland, Oregon from 1983-1987. Questions to be explored are:

1. Did Project MAIN meet the needs of the frail elderly
a) for a dependable supply of food?
b) in helping them maintain independence and autonomy?
c) in decreasing their social isolation?
d) in decreasing age segregation?

2. Did Project MAIN meet the needs of urban youth
a) in helping them achieve independence and autonomy?
b) in facilitating their transition from school to work place?
c) in providing income?

\section{THE FRAIL ELDERLY}

\section{Demographic Changes}

The United States is experiencing an unprecedented increase in the numbers of persons over 65 years of age (Eustis, 1984). In 1980, there were 25 million elderly persons, comprising 11 percent of the population. It is projected that by the year 2000 , there will be 55 million persons over the age of 65 , comprising 22 percent of the 
population. It is expected that, between 1980 and 2000 , there will be a 67 percent increase in persons 80 and over. These demographic changes are significant, especially for long-term care policy for the elderly.

The significance in the disproportionate increase in the "old-old" lies in the greater incidence of functional disability and more chronic disease among the very old. The problems concerning the quality and availability of long-term service for increasing numbers of the elderly, both now and in the years ahead, are of growing concern.

\section{Independence and Autonomy}

In 1980, Shanas found that no more than five percent of the elderly lived in institutions at any given time. However, of those not institutionalized, 10 percent required some form of home care.

Eustis (1984) defined home care as including help and services provided to persons who are unable to provide that care for themselves. She contended that the association between age and the need for such care is not necessarily precise. Health and social factors have a significant influence on functional disability. Some of the elderly are living close to the dividing line between independent living and the need for dependence on others for their survival. For some in this group of frail elderly, home care can provide the degree of assistance that allows them to live independently. Although some independence and autonomy are given up, it tends to be a gradual process, one which the elderly can tolerate.

Home care service, such as grocery shopping for the frail elderly, allows them control over which items they want and, to some degree, the time of the shopping. They can continue to decide what they want to eat at each meal and how it is to be prepared. This control over their own lives is important to their sense of independence (Ludman and Newman, 1986). 
Social Isolation

Bachrach (1980) defined social isolation as the absence of face-to-face contact with friends, neighbors, and relatives. With increasing frailty and functional impairment, social contact becomes more difficult to maintain. The frail elderly person becomes more dependent on others coming to see her/him. Although some can tolerate time alone, and even enjoy it, for others it results in feeling lonely, isolated, and depressed. For these elderly people, there is a need for increased opportunities for social interaction.

\section{Age Segregation}

Young people, adults, and the elderly have become increasingly segregated institutionally (Ventura-Merkel, 1988). The very young are in day care, separated by age. Then, the educational system segregates children according to age. Adults are separated from the young and the elderly in their work places. Some of the elderly live in agesegregated villages or apartments.

For the elderly, this presents a barrier. As they lose friends to death or increasing disability, it becomes difficult to fill these gaps. Their own increasing functional disability leads to greater social isolation and fewer opportunities to make new friends.

\section{Needs and Goals}

The frail elderly perceive their need for a dependable source of food as a primary requirement. Until this need is met, their need for socialization is perceived as of lesser importance (Maslow, 1960).

Elderly persons place a value on maintaining their autonomy and level of independence. Vogel (1983) stated that one's level of independence is related to the level of social interaction and activity. The elderly experience increasing dependence as they move toward a state of frailty. 
The frail elderly have a physiological need for food and a social need for autonomy, independence, and social interaction. They have increasing difficulty in meeting these needs by themselves and outside assistance becomes necessary to maintain an acceptable quality of life.

\section{Summary}

With the rapidly increasing number of "old-old" in the population, the need is urgent to provide the kind of care that permits them to continue to live in their own homes. They seek to maintain independence in the face of increasing frailty. With planning, independence often can be relinquished gradually and with minimum pain for the individual. Social isolation and age segregation can be mitigated in this decreasing level of independence. These elements need to be included in the overall plan for the care of the frail elderly.

\section{URBAN YOUTH}

\section{School Dropouts}

The President's Science Advisory Committee (1973) stated that there was an increasing pull between a youth in continuing school and dropping out to go to work. Young people were seeking autonomy, and a job represented increased independence from the family. However, Blake (1986 b) stated that dropping out of school curtailed career options.

Greenberger and Steinberg (1986) stated that one fourth of students failed to complete high school. In 1984, Borus observed that dissatisfaction with school is correlated with dropping out of school. He suggested that if satisfaction with school can be increased, dropping out can be decreased. 
School and Work

The organization for Economic Cooperation and Development (1984) stated that, while schools are supposed to prepare youth for future occupational roles, they operate in isolation from the workplace. Levin (1985) wrote that, while schooling is designated by our society as the primary adolescent activity, part-time work and school are not mutually exclusive. The job can reinforce learning through direct application of what is learned in the classroom.

\section{Youth Employment During High School}

Borus (1984) stated that there are two primary objectives in youth employment. The first, and most important to youth, was in providing immediate income. Secondly, it provided young people the opportunity to demonstrate their capability in holding a job. Additional benefits were the skills, attitudes, and knowledge that will help young people to perform successfully in adult roles.

Lewin-Epstein (1981) concurred. They stated that the experience of having responsibility for a set of tasks, earning money, and learning to manage it, may be important parts of growing up. In addition, youth can associate with adults in a different context from that of school. These all were helpful for a smooth transition to adulthood.

\section{Changing Demand of the Job Market}

The Organization for Economic Cooperation and Development (1984) stated:

Technological changes, political, and demographic shifts have all meant that the labor market is constantly being refashioned.

Established skills become less important, new ones take their place. Some of the latter require even less training than hitherto as complex jobs divide and become automated. Other desired skills become more comprehensive requiring higher levels of education. (p. 50) 
Stern and Nakata (1985) concurred and stated, "A major asset required by employees or high school graduates is the ability to learn and to adapt to changes in the workplace." (p. 8)

\section{Needs and Goals}

Young people have a need to acquire their own money. This provides for a greater independence from family and for their increasing autonomy. The age segregation consistent with their schooling is mitigated during employment by bringing them in working contact with adults. Many employers need interested workers at the low end of the pay scale and this can be accomplished with youth working at part-time jobs while completing their high school education.

\section{Summary}

Urban youth face increasing pressure to take a job in order to earn money, often at the expense of further education. Dropping out of school places future career choices in jeopardy. Programs that can provide young people with part-time job opportunities that broaden their sense of place in the community as well as an income can be blended with their classroom curriculum.

This presents a double advaritage to youth. Completion of high school protects them from the higher level of unemployment experienced by many high school drop-outs. The part-time job gives them work experience that later is reflected in higher wages.

\section{INTERGENERATIONAL PROGRAMMING}

The concept of intergenerational programming evolved during the last four decades as it became evident that the new residential, educational, and recreational patterns of today's society isolated the different age groups (Newman, 1980). Youth are missing the unique support and nurturing that older family members and unrelated elders 
can provide. The elderly are losing their respected role as valued persons with experience and special skills to share. Whereas youth can offer the vitality and perspective of the young, the elderly are the personal repositories of history. They provide familial and cultural continuity. They give youth a sense of their roots (Newman, 1983). Baum, et al. (1982) concurred that intergenerational programming serves to preserve continuity from generation to generation.

There is no single best definition for intergenerational programming. The concept encompasses a range of ideas. Each community has unique needs and resources which act as a guide for the evolution of programs. This results in a variety of groups in many settings generally focusing on service, education, social interaction, and support.

Intergenerational programs appear to hold great promise. They are attempting to bring back the special strengths of multi-generation communities. Ventura-Merkel stated in 1988:

Intergenerational programs hold enormous promise for helping disadvantaged young people, and for simultaneously enriching the lives of the older people involved ... For at-risk youth, these intergenerational programs offer an opportunity to develop self-esteem and competence, receive trusted advice, and combat defeating alienation; for older participants, they provide an opportunity to be useful, caring, and engaged. (p. 13)

\section{Summary}

Intergenerational programs present a workable plan to mitigate some of the problems of frail elderly and urban youth. Mutually beneficial goals can be accomplished.

There are many possibilities for intergenerational programs. Each would evolve directly from the needs of community members coupled with the unique resources of each community to meet that need. This concept has been found to be a cost-effective way to provide interactive services on a personal and community level and is why these programs have continued to proliferate over the last three decades. 


\section{OVERVIEW OF THE FOLLOWING CHAPTERS}

Chapter II is a review of selected literature related to the frail elderly, urban youth, and intergenerational programs. The needs of the frail elderly and urban youth are described, and the role of intergenerational programs in meeting these needs is explored.

In Chapter III, characteristics of intergenerational programs are defined, and selected programs are described.

The case study design is defined and discussed in Chapter IV. Sources of data are explored and strengths and weaknesses of the data are evaluated.

In Chapter V, the pilot phase of Project MAIN is described. The need for a program is explained, planning is described, and goals are set. The plan is implemented and finally the project is evaluated.

In Chapter VI, Project MAIN moves into the demonstration phase. Problems emerge in the areas of funding and training of shopping assistants. Project MAIN is terminated.

Chapter VII describes a survey of 50 frail elderly clients which produced data on the shopping service and the youthful shoppers. Further data is elicited about Project MAIN as a learning experience for youth. Qualitative data comes from community evaluations by a senior service agency, a high school, a store manager, selected parents of the participating youth, and from reports to Portland Youth Advocates.

In Chapter VIII, funding emerges as the greatest problem in the operation of an intergenerational program. In Project MAIN, this problem is magnified. Not only are there the costs of the program, but also wages for the young shoppers. One conclusion that comes from the study is the importance of the adequacy of funding. Of even greater importance is the need for ongoing funding. Without long-range commitment by funding sources, the elderly clients who become dependent on the program may be left in a worse situation than before the program. 


\section{CHAPTER II}

\section{REVIEW OF LITERATURE}

\section{INTRODUCTION}

This review of selected literature falls into three parts: the frail elderly in urban areas, disadvantaged and at-risk urban youth, and intergenerational programs which seek to meet the needs of both groups.

\section{THE FRAIL ELDERLY}

\section{Demographic Trends}

In 1981, the U.S. Department of Health and Human Services reported that, by 2030 , the projected number of persons age 65 and over would be 55 million, and Eustis (1984) forecast that this number would be reached by 2000 .

This rapid growth of the extreme elderly is not new, for in the twenty year span of 1940-1960, this group grew just as rapidly, by 154 percent. What is new is the fact that the sheer number of persons aged 85 and over is now of sufficient magnitude to have a major impact on the health and social systems.

Since at least 1940 , the major reason for the spectacular increase in the number of the "old old" had been a declining mortality. In recent decades, decline in the death rate of the older segment had been as large or larger than the decline of those at younger ages, resulting in unprecedented numbers of persons reaching extreme old age. 
Rosenwaite (1985) said that at the same time that decreasing mortality rates were occurring in the elderly, declining fertility rate in the young was resulting in relatively higher proportions of the older ages. Projections of continuing declines in mortality rates among the aged were a major factor in accounting for the large increases anticipated in the future size of the "old old" population.

The Bureau of Census (1984), showed an increase of 117 percent in the number of "old old" between 1980 and 2000 and another 44 percent between 2000 and 2020. See Table I.

TABLE I

\section{U.S. POPULATION FROM 65 YEARS OF AGE AND OLDER: NUMBER AND PERCENT OF TOTAL U.S. POPULATION FOR SELECTED YEARS}

\begin{tabular}{||c|c|c|}
\hline Year & Number in Thousands & Percent of U.S. Population \\
\hline 1950 & 12,397 & 8.1 \\
\hline 1960 & 16,675 & 9.3 \\
\hline 1970 & 20,087 & 9.9 \\
\hline 1976 & 22,934 & 10.7 \\
\hline 1980 & 24,927 & $11.2(11.1-11.3)$ \\
\hline 1990 & 29,824 & $12.2(11.7-12.6)$ \\
\hline 2000 & 31,822 & $12.2(11.3-12.9)$ \\
\hline 2010 & 34,837 & $12.7(11.1-13.9)$ \\
\hline 2020 & 45,102 & $15.5(12.7-17.8)$ \\
\hline 2030 & 55,024 & $18.3(14.0-22.1)$ \\
\hline 2040 & 54,925 & $17.8(12.5-22.8)$ \\
\hline
\end{tabular}

Source: Bureau of the Census, Series P-23, No. 78. (Vogel and Palmer, eds., 1983)

\section{Long-Term Care}

These demographic trends influenced projected needs for long-term health care, and the significance of the disproportionate increase in the "old-old" was found in the greater prevalence of functional impairment and functional disability among the very old. 
Data from the 1977 National Health Interview survey indicated the percentages of non-institutionalized old persons who had some degree of functional disability, and they found that the "old-old" were more likely to need help because of reduction in income, death of a spouse, or other losses. Table II indicates the percentage of three age groups with functional disability.

TABLE II

DISTRIBUTION OF FUNCTIONAL DISABILITY BY AGE 65+ OF U.S. NON-INSTITUTIONALIZED POPULATION IN 1977

\begin{tabular}{|l|c|c|}
\hline Age Group & $\begin{array}{c}\text { Percentage of age group with } \\
\text { some degree of functional } \\
\text { disability }\end{array}$ & $\begin{array}{c}\text { Number of people in } \\
\text { age group } \\
\text { (Thousands) }\end{array}$ \\
\hline 65 to 74 & 38.6 & 14,259 \\
\hline 75 to 84 & 48.4 & 6,652 \\
\hline 85 and older & 63.2 & 1,354 \\
\hline
\end{tabular}

Source: U.S. DHHS, HCFA, 1981. (Rosenwaite, 1985)

In 1985, Rosenwaite stated:

The size of age groups that frequently use long-term care can be predicted into the second half of the next century....It is also known that the numbers of persons aged 75 to 84 and of persons 80 and over is increasing faster than the total $65+$ population. (p. 202)

With a $65+$ population of $22,265,000$ in 1977 , the number of functionally disabled in this population was $9,580,000$. Utilizing projected populations of $65+$ through 2040 , and the proportion of functionally disabled in the 1977 population, the projected number of functionally disabled in 2040 will be $240 \%$ of the 1977 number, or $22,992,000$. This has serious policy implications.

Soldo stated, in 1980, that the elderly were an extremely diverse group, spanning a 30 to 35 year range. A 60 year old is different from a 95 year old in social, physical, and cultural characteristics, and the elderly could not be viewed as a homogeneous group. 
The distinction between "young-old" and "old-old" was made by Neugarten in 1982 , and it was not based primarily on chronological age, but on health status and social characteristics. Streib (1980) took into account age and ability to function independently, and Neugarten and Streib recognized that age and functional capacity overlapped in a population, with many exceptions among individuals.

\section{Goals of Long-Term Care}

For many older people, maintenance of independence is important, and as they begin to need some assistance, they try to preserve as much independence as possible. This is taken into account in planning for their long-term care. Eustis (1984) discussed four major goals of older persons who seek long-term care.

1) Maximum possible functioning: Curing the individual's ailment is frequently not a realistic goal when a functional impairment is due to a chronic condition or the frailty of old age. A goal can be set to help the older person achieve as much independence as possible, and function on as high a level of independence as possible.

2) Quality of life: An acceptable level of quality of life can be measured by maintaining the individual's standard of living.

3) Prolonged life:

The goal of a cure often is unrealistic but many diseases can be controlled.

This is related to maximum function and quality of life.

4) Reduced illness:

Long-term care is concerned with preventable or curable disease. Prevention is an important aspect of long-term care. (p.10)

\section{Level of Independence}

Older persons frequently sought long-term care because of functional impairment which resulted in their lower level of independence. These levels of independence were on a continuum ranging from 1) independent through 2) independence threatened, then 3 ) independence delegated to 4) dependent (See Table III). At level II of Table III, where independence was threatened, some potentially needed services were called on 
occasionally, and a reasonable goal was to maintain the elderly at this level as long as possible. At level III, where independence was delegated, many more services were needed. At first, these services were occasional, but they became more intensive, and a reasonable goal was to maintain the elderly at this level and keep them from becoming dependent.

Potentially needed services were related to the level of independence. When independence was threatened, the elderly person occasionally required home help such as chore services. When independence was delegated, the elderly person needed homemaker-chore services and assurance of meeting nutritional needs. At level II of Table IV, when independence was threatened, interventions were selectively required at times, but when independence was delegated at level III, intervention became more frequent or continuous. The goal was to maintain some degree of independence for as long as possible.

\section{Tasks of Daily Living}

Stoller and Earl (1982) reported on research of varying levels of functional capacity of 753 non-institutionalized older persons. Tasks were divided into categories of food preparation, shopping, light and heavy chores, dressing and grooming, bathing, and toileting. Five hundred eighty interviews were with elderly persons in non-metropolitan areas and 173 interviews were conducted in a standard metropolitan statistical area (SMSA).

The task of shopping indicated a need for assistance. In the non-SMSA, 10.4 percent of respondents did almost no shopping by themselves but did participate with assistance or supervision, while 12.4 percent were entirely dependent on others for shopping. In the SMSA, 10.6 percent of respondents did almost none of the grocery shopping by themselves but did participate with assistance or supervision, while 14 percent were entirely dependent on others for shopping (See Table III and Table IV). 
TABLE III

CONTINUUM OF LONG-TERM SERVICES BY LEVEL OF INDEPENDENCE

\begin{tabular}{|c|c|}
\hline Patient Characteristics & Potentially Needed Services \\
\hline \multicolumn{2}{|c|}{ I - Independent } \\
\hline $\begin{array}{l}\text { Wide range of options } \\
\text { Most are married } \\
\text { Kin and peers available } \\
\text { Activities and social involvement readily } \\
\text { available } \\
\text { Mobile as desired } \\
\text { Sociocconomic resources adequate } \\
\text { Environment unaltered }\end{array}$ & $\begin{array}{l}\text { Health assessment/maintenance/promotion } \\
\text { services } \\
\text { Health education programs/cducation for self- } \\
\text { care } \\
\text { Physical fitness programs } \\
\text { Information and referral } \\
\text { Multipurpose senior centers } \\
\text { Nursing services }\end{array}$ \\
\hline \multicolumn{2}{|c|}{ II - Independence Threatened } \\
\hline $\begin{array}{l}\text { Less wide range of options } \\
\text { Most are married but widowed are increasing } \\
\text { Kin and peers beginning to be unavailable } \\
\text { Activities and social involvement less available } \\
\text { Mobile with supports } \\
\text { Socioeconomic resources less adequate } \\
\text { Physical environment altered, such as senior } \\
\text { citizen housing }\end{array}$ & $\begin{array}{l}\text { All of the above selectively, plus: } \\
\text { Health restoration services } \\
\text { Nutrition center (congregate meals) } \\
\text { Occasional requirement for community health, } \\
\text { nurse, home help such as chore services } \\
\text { Community mental health }\end{array}$ \\
\hline \multicolumn{2}{|c|}{ III - Independence Delegated } \\
\hline $\begin{array}{l}\text { Limited range of options } \\
\text { Widowed increasing } \\
\text { Kin and pecrs are increasingly unavailable } \\
\text { Activities and social involvement increasingly } \\
\text { unavailable } \\
\text { Less mobile, even with supports } \\
\text { Sociocenomic resources are increasingly } \\
\text { depleted } \\
\text { Physical environment altered more than above } \\
\text { (such as congregate housing) }\end{array}$ & $\begin{array}{l}\text { All of the above selectively, plus: } \\
\text { Rehabilitation services } \\
\text { Day care/day hospital } \\
\text { In-home services - community health nurse, } \\
\text { home health aide, homemaker chore services } \\
\text { Escort and transportation services } \\
\text { Friendly visiting/telephone reassurance } \\
\text { Meals on wheels } \\
\text { Sitting services }\end{array}$ \\
\hline \multicolumn{2}{|c|}{ IV - Dependent } \\
\hline $\begin{array}{l}\text { Severely curtailed range of options } \\
\text { Most widowed } \\
\text { Kin and peers largely unavailable } \\
\text { Activities and social involvement unavailable } \\
\text { Largely immobile } \\
\text { Socioeconomic resources depleted } \\
\text { Physical environment transformed, such as } \\
\text { nursing home }\end{array}$ & $\begin{array}{l}\text { All of the above selectively, plus: } \\
\text { Life maintenance services } \\
\text { Institutional care, such as nursing home or acute } \\
\text { hospital } \\
\text { Hospice care }\end{array}$ \\
\hline
\end{tabular}

Source: Grimaldi, Paul and Toni Sullivan, Broadening Federal Coverage of Non-institutional Long-Term Care (Washington, D.C., American Health Care Association, 1981) (Vogel and Palmer, 1983) 
TABLE IV

POSSIBLE HEALTH AND SOCIAL SERVICES INTERVENTIONS BY LEVEL OF INDEPENDENCE

\begin{tabular}{|c|l||}
\hline I-Independent \\
\hline 1. & $\begin{array}{l}\text { Use of time in meaningful, health-promoting, self-care activities; work, voluntecrism, education, } \\
\text { self-advocacy, consumerism, political action, recreation, social involvement, hobbies, and } \\
\text { community revitalization }\end{array}$ \\
\hline 2. & Attitude development: consciousness raising and peer counseling, assertiveness training \\
\hline 3. & Assistance to cope with tirning points, anticipatory guidance - coping with life review \\
\hline 4. & Physical fitness: nutrition and weight control, exercise and sexual function \\
\hline 5. & Use of health care system: health maintenance/promotion checkups, health education \\
\hline 6. & Referral assistance \\
\hline 7. & Support clients' decisions and the right to make them \\
\hline 8. & Education for self-care \\
\hline II - Independence Threatened \\
\hline All of the above selectively, plus: \\
\hline 1. & $\begin{array}{l}\text { Health and social services, program for managing activities of daily living, periodic guidance } \\
\text { and validation of self-care behavior }\end{array}$ \\
\hline 2. & $\begin{array}{l}\text { Living with diminished capacity and impairments, teaching self-management of necessary } \\
\text { regimens, maintaining self-esteem, coping with losses }\end{array}$ \\
\hline 3. & Supporting family and pecrs as they assist client \\
\hline III - Independence Delegated \\
\hline All of the above selectively, plus: \\
\hline 1. & Frequent monitoring of self-care activities in home or health care facilities \\
\hline 2. & Direct illness care: therapeutic and rehabilitation services \\
\hline 3. & $\begin{array}{l}\text { Living with diminished capacity and chronicity; promoting self-esteem, assisting with planning } \\
\text { for use of time and energy, remolivation }\end{array}$ \\
\hline 4. & Assistance with performing activities of daily living \\
\hline 5. & Advocacy by providers, social workers, and family \\
\hline 6. & Assistance with environment modifications \\
\hline IV - Dependent \\
\hline All of the above selectively, plus: \\
\hline 1. & Continuous direct care \\
\hline 2. & Continuous assistance with and monitoring of activities of daily living \\
\hline 3. & Acceptance and coping with dying and death/terminal illness \\
\hline 4. & Continuous, direct management of necessary regimens \\
\hline 5. & Provide a therapeutic milieu \\
\hline 6. & Sensory stimulation and reality orientation \\
\hline 5
\end{tabular}

Source: Grimaldi, Paul and Toni Sullivan, Broadening Federal Coverage of Non-institutional Long-Term

Care (Washington, D.C., American Health Care Association, 1981) (Vogel and Palmer, 1983) 
From these observations, it must be concluded that shopping is one service that needed to be available to those elderly who cannot do it on their own. The elderly placed a value on maintaining autonomy and a level of independence and staying in their own homes was important (Vogel, 1983).

Difficulty with essential daily tasks threatened independence, and the frail elderly encountered this threat in the necessity to cope with grocery shopping. A shopping service that was regular and dependable could help to maintain autonomy and independence. Dependence on a shopper was more easily accepted because it could result in other areas of independence such as the elderly continuing to live in their own homes. Regular contact with a young shopper decreased the threat of social isolation for the elderly and served to decrease age segregation.

\section{Summary}

Recent demographic trends resulted in an increasing number of the "old-old." This increased the need for social and health services. With increasing age, the need for these services became greater. The greater need for assistance and increasing chronological age were not perfectly correlated. Need for assistance was more closely related to health and level of dependence.

\section{URBAN YOUTH}

\section{Introduction}

Youth encounter major changes while they are switching their primary activities from education to employment, and are faced with major decisions that could have longterm consequences. 
Youth in Transition

Most youth make some major decisions between the ages of 14 and 17, and one of the first is whether or not to continue education (President's Science Advisory Committee, 1973). They experience an increasing pull toward leaving school and taking a job which promises money and independence.

If they are to continue their education, the decision has to be made regarding the kind of education to pursue and where to pursue it. If they are to work, the youth has to decide whether to work full- or part-time, what job to take, and where.

Fourteen- to 17-year-olds are almost entirely dependent upon their families, while for older youths, the decision has to be made regarding when to leave home and where to go. The choice of work available to this group is limited and participation in the parttime labor force frequently is the only choice available. Most of the work is casual and does not provide learning experiences, but it does offer early economic experiences.

Table V shows the percentages and types of jobs held by high school sophomores and seniors in Chicago in the spring of 1980. For one-quarter of the sophomores, babysitting was the major work activity, followed by food services and odd jobs, and these three job types account for nearly $50 \%$ of working sophomores. For more than one-fifth of the seniors, store clerking was the major work activity, and food service was next, with more seniors than sophomores in this job category. Skilled trade, clerical work, and health-related jobs all showed increases over the rate for sophomores, and fewer seniors worked at odd jobs and baby.sitting. Most jobs for seniors required more skill and training.

\section{Goals of Urban Youth}

The President's Science Advisory Committee in 1973 stated that there were four primary goals held by youths. 
1) Money:

Most youth had depended upon parents for money. As their wants increased, they sought new sources of income.

2) Independence:

With a job, the youth were less dependent upon parents.

3) Autonomy:

They wanted to make decisions about their lives on their own. For this, they needed money in order to become more independent. Greenberger (1986) stated, "At the core of autonomy are the capacities to be self-governing, rather than controlled by others or their wishes, and the capacity to exist independently."

4) Learning and mastery of skills and information necessary to qualify for a job. (p. 209)

TABLE $V$

TYPE OF JOB HELD BY STUDENTS CURRENTLY EMPLOYED, BY GRADE: SPRING 1980 BY PERCENT

\begin{tabular}{||l|c|c|}
\hline \multicolumn{1}{|c|}{ Type of Job } & Sophomores & Scniors \\
\hline Odd Jobs & 8.2 & 1.9 \\
\hline Food Service & 12.2 & 16.8 \\
\hline Baby-sitting & 26.3 & 4.7 \\
\hline Farm Work & 6.6 & 3.9 \\
\hline Factory Work & 1.4 & 3.4 \\
\hline Skilled Trade & 3.6 & 6.2 \\
\hline Manual Labor & 7.4 & 7.6 \\
\hline Store Clerk & 7.2 & 21.5 \\
\hline Clerical Work & 2.7 & 9.9 \\
\hline Health Related & 1.3 & 4.1 \\
\hline Other & 22.7 & 20.0 \\
\hline Total Percent & 100.0 & 100.0 \\
\hline N & $1,392,304$ & $1,782,154$ \\
\hline
\end{tabular}

Lewin-Epstein, 1981

\section{Effect of Working on Education}

Education remained the primary task of this age group and concern was expressed regarding the effect of a job on the youth's education. In 1981, Lewin-Epstein explored the effect of time spent working on other aspects of adolescent life. He stated: 
The amount of time spent on work was unrelated to the amount of time spent on other activities in the case of sophomore students, and only a weak relationship was found for seniors. Apparently, an increase in the hours of work was associated with a slight reduction in the amount of time spent on homework and watching TV among seniors. But, on the whole, work did not seem to come at the expense of other adolescent activities measured in this study. (p. $x x$ )

Table VI shows the number of hours worked by employed students in 1980 .

TABLE VI

PERCENTAGE DISTRIBUTIONS OF HOURS WORKED PER WEEK OF STUDENTS CURRENTLY EMPLOYED, BY SEX: SPRING 1980

\begin{tabular}{||l|r|r|r|r|r|r||}
\hline & \multicolumn{3}{|c|}{ Sophomores } & \multicolumn{3}{c||}{ Seniors } \\
\hline Hours per Week & Total & Male & Female & Total & Male & Female \\
\hline $1-4$ & 30.8 & 23.8 & 38.0 & 8.2 & 6.7 & 9.7 \\
\hline $5-14$ & 32.9 & 30.8 & 35.1 & 20.7 & 18.3 & 23.0 \\
\hline $15-21$ & 17.5 & 20.5 & 14.6 & 32.9 & 29.2 & 36.6 \\
\hline $22-29$ & 8.4 & 10.5 & 6.1 & 20.4 & 21.6 & 19.2 \\
\hline $30-34$ & 4.0 & 5.3 & 2.6 & 8.2 & 10.2 & 6.3 \\
\hline 35 or more & 6.4 & 9.1 & 3.6 & 9.6 & 14.0 & 5.2 \\
\hline Mean hours worked & 12.6 & 14.8 & 10.5 & 19.4 & 21.1 & 17.8 \\
\hline Total & 100.0 & 100.0 & 100.0 & 100.0 & 100.0 & 100.0 \\
\hline $\mathrm{N}$ & $1,467,920$ & 737,571 & 722,959 & $1,838,906$ & 915,813 & 923,033 \\
\hline
\end{tabular}

Lewin-Epstein, 1981

The highest percentages of sophomores, both male and female, work 1-4 or 5-14 hours per week. As the number of hours of work per week increased, the percentage of sophomores decreased. The highest percentage of seniors, both male and female, worked 5-14, 15-21, or 22-29 hours per week. Thirty-five hours per week was defined as having a full-time job. Male sophomores worked more hours than females in categories 15-21 hours and higher. Male seniors worked more hours than females in the 22-39 and higher categories. 
Quality of the Work Experience

Steinberg (1982) questioned the value of a poor work experience and Grubb

(1985) explored the influence of poor quality work experience on youth, and wrote:

If young people work in jobs with limited, routinized, and unskilled tasks, capricious and demanding supervision, and where most of their co-workers are other teenagers, then it is difficult to see how working can enhance their responsibility, skills, integration with adults, or attachment to work. As many commentators have pointed out, the moral properties of work and the attraction of the work ethic disappear when work is no longer intrinsically rewarding, challenging, when occupations do not permit continued development and mobility, and when relationships with co-workers are either degrading (as in rigid hierarchies and competitive environments) or missing (in highly automated work). (p. 31)

\section{Disadvantages}

Freeman and Wise (1982) defined dead end jobs as those that did not offer opportunities for advancement, and offered little incentive for stable, continuous employment. They did not offer training or experience that would be useful in other jobs, but turnover rates were high. However, a differentiation needed to be made between dead end jobs taken for a limited time such as vacations, or as a necessary step toward a definite goal, and those taken for an indefinite time.

Borus, in 1984, examined the problem of high school drop-outs. In bivariate analysis, this group of students had unemployment rates more than twice as high as high school graduates and made up 48 percent of the hard-core unemployed. Lack of education was perceived as a barrier to employment by 21 percent of this group, but whether their problems arose from lack of credentials, lack of knowledge, or other factors was not clear.

Unemployment immediately following the completion of school appeared to have little effect on employment three or four years later. However, youth who were unemployed during high school were found to have lower wage rates than those with work experience during high school. 
Long- and Short-Term Advantages

Freeman and Wise (1982) found a strong relationship between hours worked while in high school and later employment and wage rates. Students who had worked during high school were employed many more weeks per year and had higher wage rates when they entered the labor force full-time than those who did not work in high school. Working while in high school might have reflected an underlying commitment and ability to perform well, while unemployment among students might have resulted in lost preparation for future work.

Stern and Nakada (1985) observed that research showed that new high school graduates experienced less unemployment and earned more money if they spent more time working in paid jobs while they were still students.

\section{Summary}

The transition period between full-time school and full-time employment presented many decisions for youth as they sought greater autonomy and a higher level of independence. However, a major goal for youth was earning money and this could jeopardize continuation of their education. Lewin-Epstein (1981) stated that part-time work and school were not mutually exclusive and Blake (1986b) suggested that classroom curriculum could successfully be blended with part-time work.

\section{INTERGENERATIONAL PROGRAMMING}

\section{Introduction}

Newman (1980) stated that historically there had been a kinship linkage between the younger and older generations, and suggested that there were shared developmental tasks. There was the need to develop and maintain self-esteem, and the young were working toward establishing an accepted identity. The elderly were concerned that their values and identity were no longer acceptable in a changing world, and both youth and 
the elderly needed to maintain links between past and future. The young needed to gain perspective about their roots and, through that, a degree of security for tomorrow, while the elderly needed to recognize that their past was connected with today and tomorrow, and they could draw on their past as a means of establishing continuity.

\section{Theoretical Rationale for Intergenerational Programming}

The theoretical rationale for intergenerational programs in which learning could occur was based on the need for contact and exchange among the generations to preserve continuity from generation to generation in society. The generations learned from one another and provided assistance in interpreting events and solving problems which affect all social members. Historical validity was grounded in the extended family model that provided the context in which social learning, support, and nurturing is passed from older to younger and, in turn, younger to older in an unending cycle (Baum, et al., 1982).

\section{Models of Intergenerational Programs}

In 1983, Newman stated that there were three significant factors associated with intergenerational programs.

1) Direction of service:
a) Elderly service for youth.
b) Youth service for the elderly.
c) Reciprocal service.

2) Intensity of contact: this is on a continuum of brief contacts and short duration to longer contacts over an extended period of time (Tice, 1985).

3) Impact of the program on recipients of the service, volunteers and staff, and the community. 
Reciprocity in Intergenerational Programs

Reciprocity is a key factor in maintaining satisfactory relationships in intergenerational contacts. Opportunities for reciprocity need to be provided and evaluated (Bengtson, 1979). Suny (1985) stated that the need to reciprocate, rather than the need for assistance, undermined the morale of the older individual.

Bengtson (1979) defined reciprocity in intergenerational programs as a balance of giving and receiving between generations. The elderly are concerned with maintaining equity in the face of dependency. They perceive aging as an exchange process in which their power was diminishing. Intergenerational programs offer an opportunity to balance the giving and receiving between generations and, for the elderly, the chance to maintain some control over their lives.

\section{Intergenerational Programming}

In 1970, ACTION generated the first systematic intergenerational program efforts, with its service learning programs. Programs were developed in 50 universities to provide opportunities for youth to offer service to the elderly (Newman, 1983).

In 1975, a fund established by The Edna McConnel Clark Foundation was used to involve older persons as contributors to enhance the growth and learning of youth in educational settings. Persons over 60 years of age volunteered to work in schools with children and youth between the ages of five and 18 years.

In 1980, the National Council on the Aging, in preparation for the White House Conference on Aging, convened a series of 24 mini-conferences to develop strategies for linking the generations. National policy recommendations were submitted to the White House Conference delegates. The report, "Older Americans as a Growing Resource," recommended that older persons be involved in teaching job-related skills and introducing youth to the world of work. 
Goals of Intergenerational Programs

Goals were identified for participants in intergenerational programs (Newman, 1983):

Goals for Elderly Participants:

1) Raise self-esteem.

2) Provide new friends and social contacts.

3) Restore confidence.

4) Allow for sharing of special talents.

5) Create an atmosphere for exchanging affection.

Goals for Youth:

1) Broaden view of life and aging process.

2) Build a sense of responsibility.

3) Develop acceptance of differences.

4) Cultivate a meaningful relationship with someone special.

5) Recognize positive role models.

\section{Summary}

Intergenerational programs hold promise for helping disadvantaged youth and simultaneously enriching the lives of the elderly (Ventura-Merkel, 1988). For at-risk youth, intergenerational programs offer an opportunity to develop self-esteem and competence, receive trusted advice, and combat alienation. For the elderly, they provide an opportunity to be useful, caring, and engaged. They bring back some of the special strengths of multi-generational communities. 
Reports of successful programs can be found in journals, but evaluations of programs that were unsuccessful or that encountered problems are more difficult to find. Analysis of successful programs is valuable in order to discover factors needed for good results, but equally important is identification of elements that result in difficulties or failure.

In 1988, Ventura-Merkel stated:

Intergenerational programs are becoming an increasingly appealing vehicle for bringing together younger and older persons through a mutually beneficial exchange. These programs promise to simultaneously meet the needs of young, old, families, and communities, and to do so cost-effectively by sharing limited resources. (p. 10) 


\section{CHAPTER III}

\section{INTERGENERATIONAL PROGRAMS}

\section{INTRODUCTION}

This chapter examines the role of intergenerational programming and identifies characteristics of these programs.

The growing field of intergenerational programming has sought to reverse the absence of mutual support and learning between youth and the elderly. Intergenerational programs have offered additional benefits in the area of service and interaction. Tice (1985) wrote that intergenerational programs involved a variety of groups in many settings. Many focused on service, education, social interaction, and support. Ongoing structured contact between young and old appears to be necessary for a successful program.

\section{CHARACTERISTICS OF INTERGENERATIONAL PROGRAMS}

Descriptions and evaluations of intergenerational programs are more effectively achieved if a number of these programs are examined carefully to determine factors held in common.

\section{A Clearly Defined Need for the Program}

Many programs had identified general needs such as independence and autonomy for both elderly and young participants. A need existed for a decrease in age segregation and social isolation. There was a need for mutual trust. These could be met at least in 
part by meaningful, continuous, dependable, and stable friendships between generations. Specific needs could be defined by the community, especially the elderly and youth. Goals were based on the specific needs of the involved generations in the community.

\section{Resources}

Newman (1980) reiterated the need for community support. Volunteers to assist staff were essential. The elderly, with their experience and skills, were valuable. Office space and transportation were needed. But, above all, financial suppori was necessary. Without dependable and continuing financing, a program could not survive.

\section{Planning and Goals}

Planning was stronger if it was based on principles, concepts, and theories such as intergenerational contact and exchange, autonomy, and independence (Baum, et al., 1982). The type of program, direction of service, and intensity of interaction needed to be described and goals clearly defined. Community involvement was sought, especially involving different generations (Ventura-Merkel, 1988). Ongoing and final evaluation needed to be carefully planned. The site of the program and time of sessions were important factors.

\section{$\underline{\text { Recruitment }}$}

A well prepared staff was required. Volunteers were needed, either prepared through experience or trained for the program, and in sufficient numbers to make the program effective.

\section{Training}

Staff and volunteers had to know and meet specific criteria and know the goals of the program. Training before the beginning of the program was important and ongoing training helped to maintain and increase the quality of the service. 
Evaluation

Newman (1983) stated that programs should be evaluated for usability and transferability for other locations. Progress toward meeting goals needed to be evaluated and goals modified or changed as indicated.

Impact

Most programs had an unexpected impact, positive or negative, on staff, volunteers, and participants. Other agencies and the community also felt the impact. These possible impacts needed to be anticipated in the planning. If this were done early in the planning process, changes could be made to alter the expected impacts.

\section{Outcomes}

The consequences of some programs may not be evident for some time. The community and agencies, as well as the participants, need to be involved in recognizing and assessing these outcomes.

\section{SELECTED INTERGENERATIONAL PROGRAMS}

Five programs are described in some degree of detail. Three of these were successful. The other two encountered difficulties.

Ventura-Merkel and Freedman (1988) gave brief reports of these five intergenerational programs which met with success. These programs utilized the knowledge, skills, and experiences of the elderly to help youth. One characteristic of all five programs was the one-to-one interaction, one elder with one youth.

\section{Youth in Service to Elders (Pittsburgh, PA)}

YISTE was established in 1982 and was one of a family of programs of the University of Pittsburgh's "Generations Together." 
Need. The need existed to bring youth and the elderly in contact with one another for supportive and stimulating social interaction.

Planning. Men and women age 55 and older were eligible. The direction of services was from youth to the elderly.

Goal. The goal was to enhance the quality of life for the frail elderly.

Recruitment. The elderly referred themselves to YISTE or were referred by families or social service agencies. The youth referred themselves or were referred by teachers, parents, or youth leaders. Most were between 65 and 80 , lived alone, and were referred to as "the frail elderly." They had limited sight, hearing, and/or mobility although they were mentally alert. They were interviewed to determine their needs, interests, and ability to benefit from interaction with a youth. The young volunteers were from high schools, colleges, universities, and youth organizations. Some had a specific interest in careers in human services or gerontology. Others were looking for a rewarding way of channeling time and energy.

Training. The youth received four hours of training and orientation in order to develop a deeper understanding of the aging process and the needs and expectations of the frail elderly. Training included discussions of any potential problems the youth might encounter and ways to meet these problems.

The youth provided a minimum of two hours of companionship a week for a period of three months. They kept a record of the visits and reported any problems to the YISTE staff.

Evaluation. Most of the evaluations came from elderly participants, as exemplified in the following contexts. Mrs. T. and her YISTE friend K. were avid readers. K. read to Mrs. T., who was visually impaired, and Mrs. T. suggested some of her favorite literature to K. Mr. V. and E. began their friendship through a mutual interest 
in sports. One of the special visits was spent enjoying a Mets' game on television. E. said, "We had a fun time watching the game.... We both enjoy watching baseball and talking about it."

Both K. and E. believed that their friendships would continue when they were no longer part of the YISTE program. This enduring quality was typical of many of the friendships formed through YISTE.

Impact. This program had an impressive impact on the frail elderly who seldom saw young people, and who now looked forward with pleasure to the visits from the youth.

Outcome. It was found that their new friendships strengthened the connections of the frail elderly to the greater community outside their homes. This led to a decrease in their feelings of isolation. After several weeks of visits by a young person, they had a more positive attitude toward themselves and the world around them. This was determined by their remarks in the interview, compared with their conservation prior to their visits with a youth.

\section{The Intergenerational Linkages Program (Ann Arbor, MI; Chicago, R; Atlanta, GA)}

Need. The education, health, and well-being of youth who were at risk of substance abuse, pregnancy, dropping out of school, or delinquent behavior.

Resources. The American Retired Persons/Retired Teachers' Association and public schools in Ann Arbor, Michigan; Chicago, Illinois; and Atlanta, Georgia implemented the program.

The program was supported with grants from the Administration on Aging; the Administration on Children, Youth and Families; and the Office of Program Development, OHDS. 
Planning. The program utilized the concepts and technologies of the TeachingLearning Communities Program, an intergenerational program begun in Ann Arbor in the early 1970s. These were based on the assumption that when mind, body, and spirit work together in balanced ways, health, well-being, and excellence of achievement follow.

Older adults were invited into classrooms and other places where youth gathered to share special interests and exchange skills. As teaching and learning were exchanged, the interactive involvement of all participants was strengthened.

The direction of this program was from the elderly to the youth. Most of the elderly came to the program site once a week, although many came more frequently, and to more than one site.

Coordination was provided by a graduate student who knew the neighborhood and the school and other program sites. A team consisted of a volunteer, age 55 or older, and a graduate student.

Goals. Education, improved health and well-being of youth, and career options were important goals for the youth. A second goal was to foster the development of responsible interpersonal friendships between youth and the elderly.

Recruitment. Older adults who serve as instructors and role models are invited into classroooms and other places where young people gather.

Training. Project staff members provided technical assistance and training but were not available for ongoing support and assistance. Attention was focused on the deeper needs of youth that ofien produced such symptoms as substance abuse and dropping out of school.

Evaluation. Like YIS'TE, the Intergenerational Linkages Program was sponsored by a university. This increased the availability of knowledgeable and well-trained people for planning and leadership roles. 
Important evaluations came from participants in the program, the elderly and the young people. One seventh grade student said, "I learned a lot from older people...about the work they used to do, what they liked about it and what they didn't like...and how they coped with what they didn't like."

One elderly man said, "I know from experience that the program enhanced the lives of the children, and that it enhanced the status of the elderly volunteers...it provided a focus for my life."

The variety and scope of activities continued to grow as older and younger people were encouraged to offer what they had to share.

Impact. A school principal was skeptical of the program at first, but at the end of a year, he saw parents who had never been in the school come to an Open House. Their children were so happy to have them there. The principal felt that this was a step in the right direction. Youth were encouraged to take a realistic look at the field of work and the steps needed to achieve their goals.

Outcome. Eight satellite programs were set up within a fifty mile radius of each of three centers. For older people who felt lonely and useless, the project gave an opportunity to interact with youth and to make a difference in their lives.

\section{Elderly-Youth Exchange (EYE) (Portland, OR)}

Need. Older people and youth needed opportunities to share their special abilities with one another. Some of the elderly were struggling to maintain independence in their own homes, but the burden of housekeeping and yard work became too great. Some youth were struggling academically and some homeless girls needed an advocate while finding a job and housing.

Resources. The program was sponsored by the Portland State University Regional Research Institute for Human Services; Neighborhood House, Inc.; and the Westside Youth Service Center. Funding was provided by the Meyer Charitable Trust. 
Planning. This program was based on the concept that youth and the elderly have something unique and important to offer each other. The direction of service was from youth to the elderly as well as from the elderly to youth.

In the employment component of the program, youth provided assistance with housekeeping and yard work to older adults in their homes, for three to four hours a week, for six months.

In the "friendly visitor" program, a young person and an older adult were matched for the purpose of friendly visiting. The youth visited the same elderly person, for one hour, once a week, for ten wceks.

In the component in which older adults served youth, the EYE program identified programs in the community that served youth and arranged to have older adults work in these settings. EYE required that the placements offer continuity of contact between the same youth and older adults.

Goal. The main goal of the program was to improve relationships between youth and the elderly.

Recruitment. Youth were recruited from the community at large. Most came from the Westside Youth Service Center's employment program. Older adults were recruited mainly from contacts made through Neighborhood House. They were offered stipends, but many elected not to receive payment.

Training. Youth in the employment program were interviewed and screened and required to attend 30 to 40 hours of orientation. This acquainted the youth with employee responsibilities and developed a sense of group identity. They began to develop an understanding of the aging process. They were instructed and observed in housekeeping and yard work tasks. 
Supervisors maintained contact with the youth and the elderly whom they were assisting. The youth were required to attend weekly supervision sessions. They received support for difficulties they were encountering and continued to learn about issues relevant to aging. In additior, youth in the friendly visitor component received brief training to help them feel more comfortable in their role of visitor.

In the component comprised of older adults serving youth, the elderly served in many settings according to their abilities and in response to many needs. They worked with foreign students studying English as a second language. They provided tutoring on an individual basis. They worked at a day camp and with CampFire Girls. They worked in a residential program for homeless girls. They were guest presenters at an alternative school, speaking on a variety of subjects.

Evaluation. Pre- and post-tests provided a scoring of measures on attitudes. Direct questions related to an evaluation of the program and whether attitudes thereby changed. It was found that there is a need to target programs according to the desired goals. If intergenerational contacts are the goal, focus on the elderly. If intergenerational relationships are the goal, focus on those youth who have a more negative attitude toward the older generations. Because both youth and the elderly can be very busy, relationships are more easily fostered when working through the school system.

Impact. The concept was to "Help each generation to see the world through the eyes of the other." The program caused the participants to become aware of personal strengths and to appreciate another's differences and similarities, the fact that each world view is different; there is great diversity. Both groups needed patience. The elderly felt increased trust and less fear of adolescents. Both groups enjoyed the intergenerational contacts. 
Outcomes. Structure and continuity are needed in order that intimate relationships have time to develop. Conversely, when the intense involvement continues for a long time, youth may experience burnout, loss of interest, and return to more negative attitudes.

\section{$\underline{\text { Summary }}$}

YISTE, Intergenerational Linkages, and Elderly-Youth Exchange were three intergenerational programs that were successful. Each was sponsored by some part of the educational system and had access to its resources and personnel. The needs, both general and specific, were clearly defined. Planning for each program was extensive and based on concepts related to the needs of the community. Training differed for each program but was given both prior to the implementation and throughout the duration of the program. Evaluation was sought from the elderly and youth in each project. Two of the programs were financially supported by grants.

\section{INTERGENERATIONAL PROGRAMS THAT ENCOUNTERED PROBLEMS}

\section{Introduction}

Two programs encountered problems in organization or in meeting goals. Careful analysis of these programs can be valuable in planning future programs by identifying areas that could lead into problems.

\section{Camp Fire's Intergenerational Program Delivery System (Kansas City, MO)}

Need. The need for this program delivery system was not identified. The emphasis was on the developinent of a system for education, and not on the needs of the recipients of the service.

Resources. The program was generated under the auspices of the Camp Fire organization for young people. 
Planning. The plan was to recruit and train older adults and teenagers to work together as a team to conduct educational programs for younger children.

Training. The elders and teenagers participated in a six-hour team-building training program. The objective was to help them become acquainted and comfortable with each other. Next, teams of elderly adults and youth spent four to six hours learning techniques for teaching a self reliance course to children in kindergarten through third grade. Following the training, the teams conducted courses once a week over a six- or eight-week period.

Goal. The goal of this program was the development of written and visual materials documenting the crucial elements of a system that could be used by a variety of human service agencies.

Evaluation. Both groups, youth and the elderly, agreed that they would have liked to get to know one another better. The elderly seemed to be more interested in the quality of interaction with the young children than in the quality of the team relationship.

\section{Problems Encountered}

Commitment of Time. This program called for a commitment of time. More time spent on bettering relationships between elders and youth was desired. A better combination of teaching and interaction might have been more acceptable to the volunteers.

Transportation. Some of the youth and some of the elderly could not drive themselves to the program site. It proved difficult to find program sites that were easily accessible to all three groups; elderly, youth, and children.

Scheduling. Three different age groups with three different lifestyles affected the scheduling of training and teaching sessions. Combining the problems of transportation and scheduling made planning for the program very difficult. 
Team building. The program depended upon building a working team of elders and youth. A knowledge of tasks achievable by the different age groups would have been helpful.

Inhibitions about Working with a Stranger. Several elderly and youth would volunteer only if they could work with a friend. They could not step outside the safety of their peer group.

Teaching Small Children. Many of the teens and elderly were intimidated by the assignment of "teaching" young children. "Storytelling" or "leading a group" were more acceptable terms.

Summary. These problems appear to have arisen out of the need for more intensive planning. Foreseeing as many problems as possible and preparing alternate plans for these contingencies might have produces a more successful project.

\section{Channel One: Senior Citizens' Food Co-Op (Rochester, MN)}

This project opened in Rochester, Minnesota in 1980.

Need. The need existed to involve youth in meaningful community activities in an effort to prevent drug abuse (Allen, 1986).

Resources. The National Institute on Drug Abuse provided seed money.

Community Support. A group of diverse people were invited to develop a plan. YMCA donated space. Carpenter and painter apprentices built shelves using donated lumber. Food to stock the shelves was obtained from churches, schools, and businesses. Students conducted fundraising projects and started a gardening project to raise produce for the co-op.

Recruitment. Students and elderly visited senior service agencies and asked for referrals of elderly who needed food assistance, and asked for volunteers to work in the project in exchange for food. 
Planning. The plan was to have youth and elders work together in the co-op. Although both groups delivered groceries to house bound elderly, in other areas there was a division of labor. The elders took home delivery orders, shelved food, weighed produce, and assisted shoppers. The youth planted and harvested a garden, and worked in fundraising projects. The division of tasks decreased opportunities for youth and elderly to interact and build trust in each other.

A second goal was to have the elders pass along or exchange skills with youth. This did not occur. A reason for this was given by an elderly individual who stated that a high level of trust of the older people by the younger needed to be established before this could happen.

Intergenerational sharing did take place between individuals but was not part of the planned operation of the project. Part of this may have been because there was no planned one-to-one interaction between a youth and an older participant. If these problems had been foreseen in the early planning, strategies could have been devised to circumvent them.

\section{Summary of the Five Programs}

In examining these programs, it becomes evident that an identified need for the program was necessary. Intensive and careful planning was essential. A basis of principles, concepts, and theory enhanced possibilities for success. The probability of problems needed to be considered and contingency measures explored. An assessment of available resources was imporiant. Community support was needed. Dependable and ongoing financial support was essential.

Goals needed to be defined clearly, and if they were described in behavioral terms, they became quantifiable. The effects of these goals would have an impact on participants in the program and on the community. The anticipated consequences of these impacts had to be considered in the initial planning. 
Even without adequate study of the need and without intensive planning, a program still may meet with some success. Channel One met the food shopping needs of a large number of elderly, but improved understanding and increased interaction between generations still were missing. However, with investment of time and effort for study of the problem and intensive planning for changing the program could enhance the efforts and improve the outcome.

\section{Factors Relevant to all Five Programs}

Analysis of reports of the five intergenerational programs revealed that they had more characteristics in common. This information can be used in planning new programs, and later for their evaluation. A matrix was constructed to facilitate this process. When successful programs are identified, they are compared with those that encountered difficulties. Differences in characteristics are identified and an attempt is made to determine why one program succeeded while the other did not. (See Table VII.)

The need for a program needs to be clearly identified and defined. Funding is an essential factor. Not only must it be adequate, but long range commitment for funding is important. Without ongoing funding, the program may have to be terminated, and those who had become dependent on it may be in a worse situation than they were in before the program starts.

Planning is an important part of an intergenerational program. An attempt needs to be made to consider all contingencies, their consequences, and plans to deal with them.

Evaluation needs to be ongoing to monitor the progress of the programs and to modify or change goals if that is indicated.

Impacts refer to the immediate effects of the program. Outcomes are the longerterm consequences. 
TABLE VII

FACTORS IN INTERGENERATIONAL PROGRAMS

\begin{tabular}{|c|c|c|c|c|c|}
\hline & YISTE & IG Linkages & E.Y.E. & Camp Fire & Food Co-Op \\
\hline Defined Need & $\begin{array}{l}\text { Bring youth and elderly } \\
\text { together }\end{array}$ & $\begin{array}{l}\text { Youth at risk of } \\
\text { substance abuse and } \\
\text { dropping out }\end{array}$ & $\begin{array}{l}\text { Better understanding of } \\
\text { youth, elderly } \\
\text { Elderly - independence }\end{array}$ & $\begin{array}{l}\text { Make positive } \\
\text { contribution to society }\end{array}$ & $\begin{array}{l}\text { Activity for youth to } \\
\text { prevent substance abuse }\end{array}$ \\
\hline $\begin{array}{l}\quad \text { Resources } \\
\text { Community support } \\
\text { Money } \\
\text { Staff } \\
\text { Volunteers } \\
\end{array}$ & $\begin{array}{l}\text { Sponsored by the } \\
\text { University of Pittsburgh }\end{array}$ & Grants, federal funding & $\begin{array}{l}\text { Sponsored by Portland } \\
\text { State University, } \\
\text { Neighborhood House } \\
\text { Sponsored by Fred } \\
\text { Meyer } \\
\end{array}$ & Grants & $\begin{array}{l}\text { Community Support } \\
\text { Grants }\end{array}$ \\
\hline Planning & $\begin{array}{l}\text { With "Generation } \\
\text { Together" }\end{array}$ & $\begin{array}{l}\text { Cooperatively with } \\
\text { AARP }\end{array}$ & Plans for three programs & $\begin{array}{l}\text { Not all contingencies } \\
\text { considered }\end{array}$ & $\begin{array}{l}\text { By diverse community } \\
\text { group }\end{array}$ \\
\hline Goals & $\begin{array}{l}\text { Enhance quality of life } \\
\text { for the elderly }\end{array}$ & $\begin{array}{l}\text { Education, health, and } \\
\text { well-being of youth }\end{array}$ & $\begin{array}{l}\text { Better relationship } \\
\text { between youth, elderly }\end{array}$ & $\begin{array}{l}\text { Develop curriculum for } \\
\text { children }\end{array}$ & $\begin{array}{l}\text { Elderly to pass along or } \\
\text { exchange skills }\end{array}$ \\
\hline $\begin{array}{l}\quad \text { Recruitment } \\
\text { Staff } \\
\text { Volunteers } \\
\text { Participants }\end{array}$ & $\begin{array}{l}\text { Youth - teachers, } \\
\text { parents, selves } \\
\text { Elderly - family } \\
\text { agencies, SCIF }\end{array}$ & $\begin{array}{l}\text { Elderly - community } \\
\text { Youth - school }\end{array}$ & $\begin{array}{l}\text { Elderly - neighborhood } \\
\text { house } \\
\text { Youth - community, } \\
\text { WYSC }\end{array}$ & $\begin{array}{l}\text { Difficulty in } \\
\text { recruitment, time, } \\
\text { transportation }\end{array}$ & $\begin{array}{l}\text { Staff and volunteer from } \\
\text { community, Elderly - } \\
\text { referred by others }\end{array}$ \\
\hline $\begin{array}{l}\text { Training } \\
\text { Staff } \\
\text { Volunteers } \\
\end{array}$ & Volunteers - 4 hours & $\begin{array}{l}\text { By project staff } \\
\text { volunteers - own skills }\end{array}$ & $\begin{array}{l}\text { Youth - } 30-40 \text { hours } \\
\text { Visitors - brief weekly } \\
\text { groups }\end{array}$ & $\begin{array}{l}\text { Required too much time } \\
\text { Did not get to know } \\
\text { other age group }\end{array}$ & Not reported \\
\hline $\begin{array}{l}\quad \text { Evaluation } \\
\text { Usability } \\
\text { Transferability } \\
\end{array}$ & $\begin{array}{l}\text { Gave youth and elderly } \\
\text { chance to form I.G. } \\
\text { friendships }\end{array}$ & $\begin{array}{l}\text { Went to where youth } \\
\text { congregate }\end{array}$ & $\begin{array}{l}\text { Attitude changes } \\
\text { evaluated - tests and } \\
\text { interviews }\end{array}$ & $\begin{array}{l}\text { Transportation and } \\
\text { timing were problems }\end{array}$ & $\begin{array}{l}\text { Goals not met, low trust } \\
\text { levels }\end{array}$ \\
\hline $\begin{array}{l}\quad \text { Impact } \\
\text { Participants } \\
\text { Community } \\
\end{array}$ & $\begin{array}{l}\text { Increase self-esteem } \\
\text { Elderly - more positive } \\
\text { attitudes }\end{array}$ & $\begin{array}{l}\text { Youth - learned how to } \\
\text { make responsible } \\
\text { decisions }\end{array}$ & $\begin{array}{l}\text { Closeness rather than } \\
\text { quantity more important } \\
\text { in a relationship }\end{array}$ & $\begin{array}{l}\text { More interested in } \\
\text { planning curriculum }\end{array}$ & Division of labor by age \\
\hline Outcomes & $\begin{array}{l}\text { Shared values, interest. } \\
\text { Increased I.G. contact. } \\
\text { Increased concern, } \\
\text { appreciation }\end{array}$ & $\begin{array}{l}\text { Parents became } \\
\text { involved. Eight satellite } \\
\text { programs }\end{array}$ & $\begin{array}{l}\text { Indications for targeting } \\
\text { programs; design and } \\
\text { structure of programs }\end{array}$ & $\begin{array}{l}\text { Difficulties working } \\
\text { with other generation }\end{array}$ & $\begin{array}{l}\text { Need one-to-one } \\
\text { contacts }\end{array}$ \\
\hline
\end{tabular}




\section{CHAPTER IV}

\section{METHODOLOGY}

\section{INTRODUCTION}

This is a descriptive study of Project MAIN, an intergenerational program in an urban setting which provided a shopping service by high school youth in behalf of the frail elderly. The project involved an urban university, high schools, neighborhood stores, and senior service agencies. The pilot project operated from June 1983 to August 1983. The demonstration project continued from October 1983 to March 1987.

\section{Location}

The urban area selected for the project had a high concentration of elderly residents and comprised five census tracts; 9.8 percent of those over 65 years of age were at or under the poverty level (U.S. Department of Commerce, Bureau of the Census, 1970).

\section{The Elderly}

All of the elderly who participated in the project had some degree of physical disability, were frail or house bound. According to their own assessment or that of a social service agency, all needed assistance in shopping for groceries.

\section{The Participating Youth}

The youth were ages fourteen to nineteen and were attending school. They were not in trouble with the law, and they had the potential to do well in school. They sought employment by Project MAIN because of interest in the program and need for a job. The 
first youths recruited for the project in turn recruited other youth interested in human service employment. The applicants were interviewed by staff members and participating youth. There were sufficient numbers of applicants that youths accepted for employment were those evaluated as dependable to meet the needs of the elderly.

\section{DESIGN OF THE STUDY}

\section{Case Study}

Project MAIN was an innovative program, lending itself to the case study method, which is useful in studying new projects (Patton, 1988). It is the method of choice for a detailed study of the people involved, and detailed description of activities. When there are unusual successes or failures, a detailed case study may generate useful information. The case study included interviews, observational data, documentary data, impressions and statements of others, and data over time. Examination of these data permitted analysis, interpretation, and evaluation.

\section{Goals of the Project}

The goals of Project MAIN were two-fold; to bring the elderly and the youth together in a meaningful way, and to provide a service needed by the elderly. The primary goal of the elderly was to secure a dependable source of food. A secondary goal was maintaining their independence.

The primary goal of the youth was employment in order to provide immediate income. This was part of their objective to attain autonomy and independence. A further goal was to acquire work experience. 


\section{ESTABLISHING THE NEED FOR PROJECT MAIN}

\section{The Elderly: Special Problems Related to Shopping}

In 1985, the Portland/Multnomah Commission on Aging (PMCOA) conducted a survey entitled "Eating for One" to identify problems of the elderly related to shopping and cooking for one. The Nutrition Committee in 1985 decided on an opinion survey of seniors by seniors. Twenty volunteers were recruited and trained by the committee. Each spent approximately four hours a day interviewing and talking to elderly shoppers in grocery stores. Over 500 elderly were contacted, and two hundred forty-three questionnaires were completed. The findings indicated that 63 percent required assistance in shopping for food. They reported that bags were too large and too heavy, check lines were too long, and fatigue contributed to confusion. Mechanical problems with shopping carts and doors added to their difficulties. Lack of transportation often was a major problem and contributed to financial problems because they were not always able to shop for the best prices.

\section{Problems of Youth in an Urban Area}

Portland Youth Advocates (PYA), in conjunction with Portland State University, in 1982 conducted a survey of Portland youth to explore the problems of youth as they themselves saw them (Pullman, 1982). High school age youth were specifically targeted, but respondents from thirteen to twenty-seven were included. Data were gathered by unstructured interviews and by questionnaires in schools and parks in all sections of the city. The sample was non-random, but varying times and locations insured a variety of respondents. The youth identified recreation and employment as their primary concerns. (See Appendix A.) 


\section{DATA COLLECTION}

The data were drawn from a variety of sources over the duration of Project MAIN, from 1983 to 1987.

\section{Survey of 50 Frail Elderly Clients}

In 1986, it was decided that 50 frail elderly clients would be interviewed to assess their satisfaction or dissatisfaction with the shopping service. The participating youth asked for this evaluation in order to help to improve their performance as shoppers. The number of clients in 1986 was less than 50, therefore the survey was extended into 1987, adding new clients until a total of 50 was interviewed.

\section{Youth, Elderly Clients, and Other People}

Once on the job, written self-evaluations came from the youth, and semi-annual written performance evaluations of the youth were conducted by staff for merit pay increases. These were compared for changes in attitudes and personal goals over time. Elderly clients often sent letters to Project MAIN giving their impressions of the youth and the shopping service. In addition, letters came from the high school staff, agencies whose clients received the shopping service, and store managers. This was a way to gauge the impact of the project on the community.

Seven of the parents of the participating youth were interviewed to determine if the parents had seen any changes in their offsprings' behavior since working for the project.

\section{Staff meetings}

Minutes from weekly staff meetings were an important source of data. The meetings were attended by staff, participating youth, and a case manager from a senior 
service agency. Content analysis was carried out on the minutes for each meeting, and combined for each year. The yearly compilations of data then were compared to see the progress of the project over time. (See Appendix B.)

\section{Reports to Portland Youth Advocates}

Project MAIN's coordinator submitted monthly, quarterly, and annual reports to the executive director of Portland Youth Advocates. These included primarily quantitative data such as cost of the project and output of service.

\section{Presentation of data}

Data that could be quantified were presented in frequency distribution and cross tabulation tables. Frequency of category data were used for excerpts and direct tabulation. Frequency of categories was presented in order by rank of frequency.

\section{CONTENT ANALYSIS}

Content analysis of the youths' journals focused on increasing independence, the participatory learning experience, and planning, implementing, and monitoring the project. Content analysis of the staff meetings was necessary to keep current with the goals of the project, those which were reached and those which needed to be modified. An ongoing assessment was needed to measure the impact of the project on the elderly clients, the participating youth, and the community.

Content analysis of letters from the elderly clients revealed satisfaction or dissatisfaction with the service received from Project MAIN. Letters from other agencies, store managers, and other community sources gave additional data on the assessment of the project from different points of view. 


\section{EVALUATION}

Outcomes were measured by satisfaction experienced by both the frail elderly and the participating youth. The elderly placed the highest value on reliability of the shopper. Youth placed value on the importance of the shopping service to the elderly clients, and their contacts with the elderly. These data were drawn from direct quotations and excerpts from written documents (Patton, 1988).

Project MAIN continued in the research and development phase and evidence of change was sought. Data documenting change came from minutes of staff meetings and reports to Portland Youth Advocates.

Project MAIN was conceived as a dynamic entity that could not be seen directly but perceived as a process that had qualitative effects on those with whom it came in contact. Therefore, data from all groups of participants were necessary to evaluate the project.

\section{STRENGTH OF DATA}

Many of the elderly respondents were aged 65 years and older and some degree of loss of memory in some of the elderly was expected. Approaching a question in more than one way was found to reach a more complete answer. With more time available the respondents gave richer details especially about topics of interest to them. New topics emerged that were important to the elderly respondents.

\section{WEAKNESSES OF DATA}

During the survey, if the elderly clients were not found at home after three attempts, the name of the client was removed from the list of prospective interviewees. This tended to exclude two classes of elderly clients, the more active and those with more frequent medical appointments. 
A second weakness was related to the age of the respondents. All but two were ages 60 to 90 . Impaired memory and confusion could be expected to occur in some in this age group (Eustis, 1984). Four of the elderly showed serious impairment and data obtained from them were of questionable value.

Further data are required to perform a more thorough analysis. Much of it can be obtained by direct questioning of the elderly clients at the beginning of the interview. An assessment of the client would facilitate the planning of a helpful shopping service. The client's placement on the illness-wellness continuum is elicited through careful questioning. This gives some information about the client's nutritional needs and the level of mobility which affects the level of independence.

The importance of independence and autonomy to the client requires further investigation. How important is it for the client to live in his/her own apartment, and does Project MAIN affect his/her feelings of independence and autonomy? Does the client feel control over the shopping - the time, the day, and exact items required.

Does the client feel lonely and isolated, and is it important to have a young shopper come in on a regular, dependable basis? Or is the client intimidated by a young person, and does he/she feel that the shopping service is an invasion of privacy?

How often does the client see grandchildren or other young people, and what do they talk about? Do the young people seem different from people of the client's age group, and are the differences distasteful? These data facilitate an analysis of age segregation.

Data dealing with the concept of reciprocity are needed. Project MAIN is a free shopping service, so a question is asked to determine if the client is comfortable with this aspect. Does the client feel the need to return the favor, so that there is not the feeling of receiving charity or being under obligation? In what ways could the client reciprocate, and would the client feel more comfortable? 
Data are needed on how the clients managed to get groceries before Project MAIN started its operation. Was that assistance satisfactory and is it still available?

Written reports need to be consistent, detailed, and dependable; such as the number of clients in place of the numbers of trips, in order to determine the number of clients served.

Recruitment criteria for youth need to be consistent, detailed, and objectively reported.

A number of written tests would give data on a youth's preparation for a job, by their acquiring communication skills and knowledge about gerontology and nutrition.

Staff meetings are a source of valuable data, but the minutes need to be clear and concise and follow a consistent format.

All of these additional data need to be concise but with adequate detail, clear, and as objective as possible. 


\section{CHAPTER V}

\section{IMPLEMENTATION}

\section{THE PILOT PHASE OF PROJECT MAIN \\ SUMMER, 1983}

\section{Introduction}

The need for meaningful employment for youth and the need for assistance with shopping for the elderly had been identified and resources for the project had been secured. Intensive planning had taken place over a number of weeks and goals of the projected program had been defined. Youth had been recruited and a plan of action for recruitment of elderly clients was ready for implementation. Plans for training the youth had been completed. Ways of evaluating the project, its impacts and outcomes, had been discussed. The pilot phase of Project MAIN was ready to begin in June 1983.

\section{Beginning the Pilot Project}

The pilot phase of Project MAIN started in June 1983 and terminated in August 1983. It was staffed by the director and three graduate students. The participating youth attended morning and afternoon sessions, Mondays through Thrusdays, and were paid the minimum wage for the hours spent with Project MAIN.

\section{THE TARGET AREA}

The target area for Project MAIN was an urban neighborhood in Portland, Oregon. Census reports of 1980 (U.S. Department of Commerce, Bureau of the Census, 
1984) indicated that this area had a high percentage of elderly individuals. Many were frail and lived alone. Two-thirds lived on four hundred dollars a month or less. Many more lived on four to five hundred dollars monthly.

This area of the city had a long standing and extensive network of service agencies for the elderly and disabled. This presented difficulties in introducing a new and innovative program. Many of the existing programs held the stereotype of youth as unreliable, incompetent, immature, and even perhaps dangerous if the media was to be believed. Youth had to establish themselves in the eyes of these agencies as trustworthy and dependable, and this had to be established through performance over time.

\section{RESOURCES}

Funding

Major funding for MAIN was provided by private foundations including the Collins Foundation, the Herbert A. Templeton Foundation, the Aetna Life and Casualty Foundation, and the Deluxe Foundation (Blake, 1985). The program's budget was $\$ 60,000$ per year with approximately $\$ 99,000$ representing volunteer and in-kind contributions. No monetary support came from the city or state.

\section{Community Support}

Good relationships were developed with the managers of grocery stores in the target area. The manager of one store agreed to participate in on-the-job training of the participating youth.

The high school in the target area donated space in the school as a base of operations and participated in planning for training that would meet educational requirements for high school credit. A senior service agency assisted in designing the program for the training the youth would need in order to be prepared to shop for the frail elderly clients. 
Affiliation with Portland State University was important. Faculty were available for consultation and teaching classes in areas of their expertise. Graduate students functioned as staff, and shared in the teaching.

With funding and support of the community assured, Project MAIN was ready to start planning for the shopping service.

\section{PLANNING}

\section{Project Oriented Learning: The First Element}

Project MAIN was planned on the basis of four interrelated elements (Blake, 1985). The first was project oriented learning.

Relevant classroom curricula were blended with part-time jobs. Thus, learning was reinforced through direct application to community needs. As community needs were observed, knowledge from the classroom was utilized in planning and testing solutions. The opportunity to apply newly gained information helped to integrate theoretical knowledge with practical experience. As the youth applied their knowledge, they felt competent and self-confident, and were motivated to continue learning.

\section{Active Youth Participation: The Second Element}

Project MAIN was a participation-based youth employment program. It was designed so that youth actively participated in planning and evaluation, as well as operating the shopping service. The youth studied shopping problems encountered by the frail elderly and disabled, and generated solutions to those problems. They learned why grocery shopping was important to their clients, and how they could most effectively organize and deliver the service. 
Inter-Age Contact: The Third Element

It was important to plan for frequent contact between the frail elderly and the participating youth. Frequent face-to-face interaction would be an effective means of breaking down social stereoty'pes, alleviating mutual fear and alienation (Blake, et al., 1983). Each elderly client would have the same youth do his/her grocery shopping over a period of weeks or months. This would provide an opportunity to interact frequently in a meaningful context.

Establishment of New Organizational Linkages: The Fourth Element

The Youth Employment Planning Team initiated collaboration among Portland State University, participating high schools, and community agencies (Blake, 1985). By encouraging collaboration in all phases, shared ownership of the project was fostered. As visibility of the project became established and trust in the reliability of youth increased, Project MAIN became part of the network of senior services in the target neighborhood.

\section{Quality of the Project MAIN Experience}

For youth, the experience was broad, offering contacts with several elderly clients, the senior service agencies, and the participating grocery store managers. For the elderly, the experience was more restricted, usually to one youth who did the regular grocery shopping.

The experience was bi-dimensional. Mutual exchange occurred between youth and the elderly. What was exchanged was different but gratifying to each.

\section{GOALS OF PROJECT MAIN}

The Youth Employment Planning Team had delineated the goals that they hoped Project MAIN would accomplish (Blake, 1986a). 
The first goal was to create a participation-based employment project that would smooth the transition from school to work by enabling youth to gain hands-on experience. Project MAIN was a program planned to employ and train youth to provide a high quality and dependable shopping service to frail elderly.

The second goal was to demonstrate the feasibility of blending classroom curriculum with part-time employment.

The third was to establish new organizational linkages among a university, local high schools, youth agencies, and senior service agencies as a means of narrowing the gap between schools and the community.

The fourth goal was to broaden the variety of primary care services provided to the frail elderly as a means of maintaining their independence and self-sufficiency. This need for independence and autonomy is equally present in the youth and is assisted by part-time, meaningful, career-oriented employment offered by Project MAIN.

A further goal for the frail elderly was to decrease their isolation through regular visits by the youth who did their shopping. Once they knew that their need for a reliable supply of food was assured, friendship between the young shopper and the elderly client was likely to grow.

These were long-term goals and could only be accomplished over time. Small steps toward accomplishing this would need to be monitored by ongoing evaluations to detect small changes indicating movement toward the goals.

\section{RECRUITMENT}

\section{Youth: Shopping Assistants}

For the pilot project, there were six teenage boys and three girls (Blake, et al., 1983). Six of the nine were low income as measured by the CETA Summer Youth Employment Program guidelines that were used to certify youth for employment. Three 
were from middle income families. They were hired through a city-funded summer jobs program with no family income restrictions. Different funding sources enabled Project MAIN to employ a diverse group of youth; delinquent, economically advantaged and disadvantaged, white and non-white.

\section{Elderly Clients}

Blake, et al. (1985) reported that Project MAIN employed two approaches to attract the frail elderly to the project. The first involved direct contact with the elderly and disabled through public speaking appearance, door-to-door leafleting, radio and television public service advertising, and by speaking to shoppers individually at checkout stands. The youth made most of the contact in this first approach. These methods met with limited success in recruiting new clients.

The second approach was much more successful. Most new clients came through referral by senior service agencies in the target area. The mobile assistants accompanied agency staff in their shopping van to the home of elderly clients. This official introduction by agency staff provided assurance to the elderly. Once a small shopper base was established, other referrals came directly from the senior service agencies, hospitals, and housing managers.

\section{TRAINING THE MOBILE ASSISTANTS}

Action learning was the teaching method of Project MAIN. Aronstein and Olsen (1974) stated:

Action learning... is based on the premise that the twelve elementary and secondary school years are too long for young people to remain isolated from the responsibilities, issues, and rewards of practical involvement in the world outside the schoolhouse. Opportunities for involvement for constructive interaction within the community can be found through student involvement outside the classroom.... We must 
safeguard against the exploitation of young people by making sure that action projects undertaken are substantial, not token in nature; fulfill community needs and not personal wants only; provide for genuine human service, not emotional release only. (p. v)

Classroom training of youth participants was necessary to provide the knowledge and skills that would be needed in order to provide a shopping service for the frail elderly. It was scheduled for 14 - 20 hours per week for four weeks in the pilot phase of the project. Classes and hands-on training took place before the participating youth started the grocery shopping, and on-going education was required for continuing employment.

\section{Gerontology}

Some of the youth had little or no previous contact with the elderly. They had to learn quickly more about this age group. The goal of these classes was to sensitize youth to medical and emotional needs of the frail elderly, and social needs and contributions of the elderly were also studied.

\section{Nutrition}

Nutrition was an area with many facets. Focus was on the special needs of the elderly. Weekly pot luck lunches for youth and staff facilitated practical discussions about nutrition and introduced new eating styles to all.

\section{Guest Speakers}

Professionals from the business community and faculty and graduate students from Portland State University gave lectures on topics from their area of expertise, including grocery economics, sensory changes with age, urban demographics, wheelchair use, types of physical disabilities, and cultural difference. Weekly time was set aside to discuss policy; e.g., whether or not to buy cigarettes for the elderly who requested them. 
Communication

Written reports were prepared by the youth, and oral communication was practiced in classes, and in discussions with agencies and clients. The youth prepared oral presentation to be used in marketing the service. The youth were required to keep daily journals in which to record their thoughts and feelings. One youth wrote in her journal:

The training I received help me immensely in my own nutrition. I learned a lot about the food chain and eating simple foods....I passed all this information on to my mother who used it to get the whole family to eat better. (Schindler, 1983)

Individual reading assignments, group training seminars, and group discussions of the reading materials were a regularly scheduled part of the training process.

\section{Clear the Air}

These were regular sessions: "... a time for everyone to be open with each other and say what was on their minds; complaints, suggestions, good feelings and bad feelings, in a confidential, warm setting." This brought the group closer together and helped to deal with interpersonal conflicts that were affecting the group. These sessions transformed tensions between individuals into group problems which then could be dealt with on a less personal level.

\section{Hands-On Training}

Afternoons were devoted to hands-on activities. Telephone techniques and etiquette were practiced. Public speaking to groups in high rise apartment buildings publicized the new shopping service. A grocery store was visited and the youth became familiar with the general layout and the positions of specialized articles such as diet foods. Reading and understanding labels on foods was important for the youth and proved to be equally important for the people they shopped for. 
If the youth indicated that they needed more information in any area, or more time practicing a hands-on procedure, i.e., wheelchair use, this became part of the planning and was included in classes and hands-on practice.

The participating youth became familiar with the target area; its stores, hazards, and features. They visited the stores in which they would be buying groceries, met the store personnel, and became familiar with the physical layout of each store.

By the fourth week of training, the youth were eager to start their job of shopping for their clients. Classes continued once a week, and their experiences with their clients were discussed and used as learning experiences for the group.

\section{THE NEIGHBORHOOD}

The area of northwest Portland in which the frail elderly clients lived was relatively level, with no steep hills. However, two of the high-rise apartment buildings where many of the clients lived were slightly uphill from two of the supermarkets. For the frail and for those in wheelchairs, the slight rise in the streets when carrying bags of groceries made a shopping trip difficult. A very few could manage if someone accompanied them, but most round it necessary to have someone else do the shopping for them.

This population of frail elderly was clustered in and around four high-rise apartment buildings. Northwest Towers, Williams Plaza, and Gallagher Plaza were under the management of the Housing Authority of Portland. Marshall Union Manor was under the supervision of a railroad union.

Other clients lived in small hotels and in large houses that had been subdivided into small apartments. These and the high-rise apartments lay within a 72 block area, between 18 th and 24 th avenues, and Burnside and Northrup streets. Groceries were available at three supermarkets and 12 small grocery stores. Within this area were four 
churches and one temple. Another temple and two churches lay just outside, but within walking distance of this neighborhood. A bus line ran along the south and west perimeters and passed by a large hospital.

This was a neighborhood that was convenient for elderly residents, but as they became older, frailer, or disabled, they became aware of difficulties, especially in ensuring a reliable supply of groceries. It was to this group that Project MAIN offered a shopping service.

\section{THE SHOPPING SERVICE}

\section{Introduction to Clients}

Shopping began on week four, after a number of clients had been identified. At first, the Project MAIN participants accompanied the staff of a senior service center in their shopping van. In a short time, the elderly who needed someone to accompany them on shopping trips were referred directly to Project MAIN, and those who needed someone to do the shopping for them were soon referred.

Frequently, the elderly client had the shopping list made out when the youth arrived at their door according to a pre-arranged time. The Mobile Assistant went over the list carefully, asking for specific name brands, and sizes. This also provided an opportunity for the shopper to share nutritional knowledge with the elderly client. Sometimes the shopper made out the shopping list with the help of the client.

\section{The Elderly Clients}

Most of the elderly clients were between sixty-five and ninety years of age. All had some physical limitation. Most were home bound, and for the remainder, shopping alone for a adequate supply of groceries was almost impossible. They had been dependent on volunteers from Friendly House, relatives, and neighbors for a supply of food. 
Many were at or near the poverty level, but everyone had some treasured possessions that conveyed a feeling of home. Some had pieces of beautiful furniture or paintings and books. Others were busy with crafts and produced articles for their own use or for friends.

\section{Evaluation of the Shopping Service by the Elderly Clients of the Pilot Project}

The pilot project was scheduled to end toward the end of August 1983 when available funds would be exhausted. It was important to get an evaluation from the ones most directly involved, the elderly clients. A staff member visited nine of the clients who had received the shopping service from seven of the participating youth. There was no planned selection of clients; it depended on who was at home.

Seven of the nine clients were eighty years old or older. One man was sixty-nine, and one woman spoke Spanish and very limited English. Her age was not ascertained. She was the only one of this group who required escort service, and one of the youth accompanied her on her grocery shopping trips. The remaining eight required a shopper to do the actual shopping of groceries. For some, there was also a need to have someone put the groceries away.

\section{Evaluative Data}

Five of the clients were women, four were men. Six had been introduced to Project MAIN by the senior service agency. One had learned about the shopping service through an article in a newsletter and a notice in an elevator. Two of the elderly could not remember how they learned about Project MAIN.

They were fiercely independent and fought off suggestions that a move to a nursing home would make life easier for them. They were grateful for the service offered by Project MAIN, and to the youth who ensured them a dependable supply of food. 
Once their food supply was assured, there seemed to be time and energy for friendship to develop. Not all of the elderly and youth became close friends, but even for those who did not, they were able to tolerate different values and opinions.

The elderly clients were asked how they would evaluate the service. Most of their responses were positive. The youths:

- Follow directions well.

- Always on time.

- Very quick with the shopping.

- Efficient; use good judgment.

- Gets special items such as unsalted crackers.

- Do extra jobs; once washed some china I could not reach.

- Look for extra things to do.

- Occasionally have to return items to the store for exchange.

- Once bought the wrong item - two percent instead of whole milk.

Only one negative evaluation presented a problem. A ninety-five year old man complained that the youth doing his shopping was black and male. According to him, anyone doing his shopping had to be a "white girl." The group of Project MAIN participants met to discuss how to cope with the problem of any client who did not want to accept the services of a shopper because of race, religion, or gender. The decision was made that rejection of any member of Project MAIN was rejection of Project MAIN, the shopping service. The policy remained to send whoever was available for the shopping when the request was received. 
perceived this as an affront to the youth and stated that placing high expectations was a better strategy and did not insult the youth.

\section{$\underline{\text { Staff Meetings }}$}

Staff meetings were held weekly to review the events of the week and the progress of the project. The participating youth kept journals to record their own experiences. With information from these sources, it was possible to evaluate Project MAIN. Progress was measured against the original goals.

Goals for the participating youth had been reached. They were employed for twenty hours a week and were paid the minimum wage. Class work and hands-on training were related to the needs of the home bound elderly. When problems arose, the youth participated in researching the area of difficulty and shared in planning and evaluating an answer to the problem.

Active youth participation made itself known at an early stage. A fifteen year old girl wrote in her journal:

I felt I fit better here than anywhere else I've been. Usually, I am just there, but in Project MAIN, I have a say. I can voice my opinions and give suggestions and they are acknowledged. (Schindler, 1983)

The grocery section of the store where the youth would shop for their elderly clients was being remodeled. One of the boys saw that the spaces between the check-out counters were too narrow for wheelchairs. He discussed this in class and then went to the store manager with his observations. Plans were drawn to incorporate wider space between all check-out counters.

The elderly clients had a new agency that could provide a regular dependable shopping service. A frequently heard remark by an elderly client was, "Other teenagers do 'so and so,' but not my shopper." 
The elderly clients had a new agency that could provide a regular dependable shopping service. A frequently heard remark by an elderly client was, "Other teenagers do 'so and so,' but not my shopper."

Networking was an integral part of the project. A university, a high school, local grocery stores, and social service agencies had been able to work together to meet a need of the elderly in the neighborhood.

The consensus was that the project had been a success, and well trained and prepared youth could work toward meeting a community need. Youth had proved to be reliable and dependable workers. All looked forward to the continuation of Project MAIN as soon as funds were available. 


\section{CHAPTER VI}

\section{DEMONSTRATION PROJECT:}

FALL 1983 - WINTER 1987

\section{PLANNING}

The demonstration phase of Project MAIN began late in the fall of 1983 and was in full operation by the beginning of 1984. The hours that the youth worked were dictated by their school schedule. Students began by earning basic wage, and in addition, they received school credit for their participation in Project MAIN.

Planning was an ongoing activity as continued evaluation suggested changes that promised to improve the operation of the project. Weekly staff meetings were a high priority. Staff met with the participating youth. Input came from all staff members, and the youth were an integral part of the organization. They offered evaluations, criticisms, and suggestions for changes, and they felt ownership of the project.

Assessment of the operation of the project with regard to working toward goals was a continuing activity. Changes in goals were made as the goals were met, or a new focus was needed. As changes were implemented, assessment of the changes became part of the process of evaluation.

\section{Goals}

Goals for the project remained the same as for the pilot project. A long-term goal was to prove the vaiue of Project MAIN to the community, and hope that a community agency, a store, or a city, county, or state agency would take over the funding and operation of the project. 
When Project MAIN resumed in the fall of 1983, it faced changes. The youth were in school and their work hours had to be reduced to eight hours a week. The available times for work were restricted to free periods, after school, and weekends. Scheduling Project MAIN classes and training periods was difficult. In order to earn one high school credit, the youth had to participate in a minimum of one hundred thirty hours of activity (see Appendix C) and the maximum number of hours of participation was limited by school requirements. Ongoing education was a criterion for continuing employment by Project MAIN. As the number of elderly seeking help with shopping increased, the available time for ongoing training of the youth decreased. Time for necessary tasks such as "clear the air" and for social interaction became increasingly hard to find. The commitment of the participating youth, their energy, and their enthusiasm were important factors in keeping Project MAIN viable in the face of difficulties in scheduling.

\section{Recruiting}

For demonstration project, youth were recruited from local high schools. Most came from a school within the target area. Recruiting within the school came from referrals by youth initially employed by Project MAIN. Interested youth made formal application for employment by Project MAIN, and final decisions were made by Project MAIN youth and staff.

Recruiting of youth and the elderly was an ongoing process. Youth left Project MAIN employment, as their interest changed, upon high school graduation, or maturing to other more traditional jobs. Some youth who left Project MAIN continued to shop for their clients on a voluntary, private basis in order to maintain their relationships. Many of the elderly remained as clients for months or longer. Some no longer needed the service because of improved health. Others moved to a nursing home or a different living 
arrangement where shopping no longer was a problem; some died. The problem would be in balancing the number of elderly needing the service with the number of youth employed by Project MAIN, which in turn depended on funds available.

\section{Training}

Hands-on training and formal classes were necessary before new youth assumed the responsibility of shopping for elderly clients. The difficulty arose when one or two new shoppers were recruited at a time. This meant that classes and hands-on training had to be repeated frequently which was costly in terms of time and energy. As time went on, some of the more experienced youth began to teach the formal classes. This proved to be adequate in terms of basic information, but the content lacked depth. This was shown in a decreased sensitivity to the emotional needs of the clients. Gerontology sensitized the youth to medical, nutritional, and social needs of the elderly, but it was awareness of the consequences of a dependable shopping service that produced a change in attitude of the new youth.

Skills in verbal and written communication affected the shopper-client relationship and the working relationships with co-workers, agencies, store personnel, and housing managers. These skills were essential in the efficient and smooth operation of the project. The youth worked at acquiring them through hands-on experiences, with critical evaluation from peers and staff.

\section{Co-Location}

One of the earliest problems that arose when Project MAIN resumed was where to base the service. Two possibilities existed - in the participating high school or in the senior service center. Both presented advantages and disadvantages. 
In the high school, Project MAIN shared the same location as other classes. There was a minimum of lost time and contact with teachers helped the teachers gain a greater understanding, and increased sympathy, with the project.

Working in the school environment with the participating youth also had disadvantages. The familiar environment was comfortable for the youth, but there was not much increase in contact with adults in a working situation.

One of the greatest disadvantages was that telephone messages for Project MAIN did not come to the school, but were received by the senior service center. Another was that there was no consistently quiet place for meetings and classes. Finally, the school would be closed during the summer and there was no guarantee that space in the school would remain available.

Project MAIN moved to the senior center although it also had no consistently quiet place for meetings and classes until a conference room was made available for most meetings. The receptionist received telephone messages which facilitated faster response for requests for shopping assistance. The participating youth shared an office with two case managers which was noisy with many interruptions by clients and staff. However, this turned out to be advantageous since the case managers and agency staff became more familiar with the youth and the project, they became even more cooperative. The case managers and youth shared information about the elderly clients. A case manager said that the youths became a second set of eyes and ears, enabling the case managers to become aware of problems that an elderly person might be encountering, such as negative reactions to medication or summer heat (Blake, 1986a). There was a feeling of shared responsibility for the elderly clients, and the youth had the experience of working with adults in a professional environment. 
Reciprocity

Project MAIN was a free shopping service for frail elderly and disabled elderly people. For some, the free aspect was acceptable because they felt that in their active years, they had paid ahead for this assistance. For others, they felt uncomfortable accepting help and giving norhing in return. Some felt they were accepting charity and did not like that.

Those who were not comfortable accepting the free shopping service found their own ways of giving something in return. The most frequent way was by gifts of food. Freshly baked cookies awaited some of the shoppers. Others were given sweet rolls, soft drinks, and special candy from a client who had owned a candy store. One client served lunch to her shopper occasionally.

A few clients found other ways of "paying their way." One gave her shopper five dollars each time with instructions to put it in the bank for future college expenses. Another was replacing a piece of furniture and gave the old piece to her shopper. Occasionally small checks were sent to Project MAIN or Portland Youth Advocates. It appeared that the clients found ways acceptable to them of paying for the service, but it suggested that this should be taken into account in future planning.

\section{Money}

Funding the project continued to be a serious problem. Some money came from grants, but no money was forthcoming from the city, county, or state. Sources of earlier grants were less willing to finance an ongoing project. The service continued to be free to the elderly clients although there was discussion about charging, possibly on a sliding scale. It was decided that the service would continue being offered "free of charge" because of the accounting difficulties inherent with this type of organization. 
Other difficulties related back to these financial problems. There was not enough money to pay for a director, and for a short time, a graduate student assumed this responsibility. Later, the position was taken over and shared by three participating youth. They had been involved in the pilot project and their leadership was satisfactory. When seasoned youth left the project or took on training responsibilities instead, leadership responsibility was taken over by other participating youth who had not had the pilot project experience. The teaching which had been assigned to youth with some experience in the project covered the salient points but lacked depth.

Another related problem arose with the increasing number of clients. In the early planning, there was no need to limit the number of clients to be accepted for the shopping service. Now, although demand had grown steadily, there was no money to hire additional youth, and the increase of time needed for shopping came at the expense of classes and meetings. The "clear the air" meetings became infrequent and quality of interactions with the elderly and other youth diminished. Classes and meetings were not attended because of the pressure of shopping for more clients. This resulted in less well prepared youth which was evident to the senior service agency and resulted in less support from them.

Financial problems led to anxiety among the youth whose jobs were at stake. As the clients became aware of the situation, they also were concerned, wondering how they would get their groceries and feeling frustrated at seeing such a well conceived project threatened. This negated the increased peace of mind that it was hoped the shopping service would give them.

\section{Termination of the Shopping Service}

By March 1987, Project MAIN had exhausted its funds. None were forthcoming. There was no other option but termination of the project. 
The participating youth were left without jobs, but of equal or greater concern to them was the future welfare of their clients. The caseworkers and volunteers at the senior service agency were going to have to take over the shopping and this was going to place a heavy burden on them. The youth were concerned about the dependence the clients had come to place on their shoppers. Besides regular supplies of groceries, friendships had evolved between youth and the elderly. This was not so easy to replace. Some of the young people planned to continue to see their elderly friends on their own time, but all recognized that the youths' time was limited. Project MAIN had been of benefit to the elderly clients, but its termination had left them with a gap in their lives.

\section{Door to Door}

Dr. David Berger brought a new grocery shopping service to Portland in 1990. It is financed by grants from foundations, local donations, and a sliding scale of fees, based on size of grocery orders and the client's income. This fee may be waived for clients on Medicaid or on recommendation of the case manager.

Door-to-Door is staffed by a director, an assistant, a secretary, and approximately 60 volunteer shoppers. The shoppers deliver groceries in their own cars or in the agency van, and like Project MAIN, the clients have the same shopper each time. Approximately 165 frail elderly receive the service and this shopping service takes a heavy load from senior service agencies, as well as providing the home-bound elderly with a regular dependable supply of groceries. Its utilization of volunteers instead of paid shoppers permits it to operate on a much lower budget, and its sliding fee scale removes much of the feeling by the elderly of having to accept charity. A small number of high school students volunteer to shop and deliver groceries, but this agency is not planned to address the problems of youth. However, it has successfully replaced Project MAIN in meeting the grocery shopping needs of the elderly. 


\title{
CHAPTER VII
}

\author{
ANALYSIS
}

\section{INTRODUCTION}

The planning for Project MAIN was based on underlying theories. The basis for the focus on the needs of two different age groups for autonomy and independence was the theory of growth and development (Vogel, 1983). Maslow's hierarchy of needs explained the necessity of meeting basic physiological needs such as food before love, belonging, and esteem (Corsini, 1973). Exchange theory detailed the need of the elderly to reciprocate by means of gifts as an attempt to balance the giving and receiving between generational (Bengtson, 1979). A training curriculum for the youth was based on learning theories (Aronstein and Olson, 1974). The focus was on action-oriented learning and full participation in the process of providing a shopping service for the frail and disabled elderly.

A survey of fifty frail elderly clients was undertaken to determine their satisfaction or dissatisfaction with the shopping service. Data collected over time were analyzed for comparison of the initial expectations of the Project MAIN participating youth with their actual experiences during the time that they shopped for the elderly clients. Evaluations were obtained from the senior service center officials for effects on the frail elderly, and evaluations from the high school teachers and from parents of participating youth for their observations of the effects of Project MAIN on participating 
youth. Monthly, quarterly, and annual reports to Portland Youth Advocates from the director of Project MAIN gave information of output. Careful analysis of these data gave indications of the progress of Project MAIN during the time that it was in operation.

\section{EVALUATIONS OF AND BY MOBILE ASSISTANTS}

\section{Survey of Elderly or Disabled Clients}

Fifty of the elderly who received Project MAIN shopping service were interviewed. Seventy-eight percent of those interviewed were between sixty and eightynine years of age. There were more than 5 times as many women as men -42 women and eight men. Of these, one man and four women did not give their ages. (See Table VIII.)

TABLE VIII

PROJECT MAIN SURVEY: $1985-86$ FREQUENCY DISTRIBUTION OF AGE BY SEX

\begin{tabular}{||c|c|c|c|c|c|c||}
\hline \multicolumn{1}{|c}{ Age } & Number & Percent & Number & Percent & Number & Percent \\
\hline Under 50 & 1 & $2 \%$ & 1 & $2 \%$ & 2 & $4 \%$ \\
\hline $50-59$ & 0 & 0 & 1 & 2 & 1 & 2 \\
\hline $60-69$ & 3 & 6 & 7 & 14 & 10 & 20 \\
\hline $70-79$ & 3 & 6 & 14 & 28 & 17 & 34 \\
\hline $80-89$ & 0 & 0 & 12 & 24 & 12 & 24 \\
\hline Over 90 & 0 & 0 & 3 & 6 & 3 & 6 \\
\hline Refused & 1 & 2 & 4 & 8 & 5 & 10 \\
\hline Total & 8 & $16 \%$ & 42 & $84 \%$ & 50 & $100 \%$ \\
\hline
\end{tabular}

The guided interview provided structure to ensure that certain areas were covered, but the informal approach to the interview encouraged many spontaneous responses. See Appendix E. These were tabulated and further exploration of them gave information on those topics considered most important to the elderly. (See Appendix F.) 
The results of the interviews were shared with the youth shoppers. The data were of interest to the youth, especially those from clients for whom they shopped. The favorable comments gave positive reinforcement, and criticisms provided guidance to areas that needed improvement. (See Table IX.) The fifty elderly clients had similar responses when asked about their shoppers. They found the youth friendly and courteous but dismissed these questions quickly. They wanted to discuss dependability and trustworthiness, and wanted to discuss these at some length (see Appendix F). Their responses were tabulated. The number of responses varied because different respondents chose to address only certain items. Consequently, the sample sizes cited below will vary accordingly.

Twenty out of twenty-two respondents rated the shopping service as good. However, some qualified this assessment as good compared with shopping done by a different person each time, or having to depend on a neighbor or a busy relative. Eleven out of twenty-two respondents said that the best aspect of Project MAIN was its availability, either by referral by a case manager, or by a direct phone call to Project MAIN. Six out of nine respondents said that they did not trust their shopper. Two said that they need time to be assured of a shopper's trustworthiness, and until then they cannot feel trust in the youth. Only one client said that there had been a question about correct change.

The worst aspect was broken appointments. Of 24 respondents who discussed the shoppers' dependability, 14 stated that they found their shoppers undependable. Six out of 9 found them untrustworthy. Eleven out of 29 who responded stated that the best aspect of the service was its availability. Four stated that their survival depended on it. Four said that the best aspect was. its dependability. Nine gave their opinions of the worst aspect of Project MAIN. Four cited broken appointments, and two said they could not depend on the service. 
Summary

Less than half of the total of 50 respondents surveyed rated the service as good, and the best aspect was its availability. The worst aspect was broken appointments.

\section{Comparison Between Initial Expectations and Later Experiences}

From application forms submitted by youth wanting to work for the project, information was drawn regarding the benefits they expected from working for Project MAIN. See Appendix D. From the participating youths' self-evaluations and their evaluations by coordinators, data were obtained listing experiences they actually had. Although the youth submitting applications and those later evaluated were not necessarily the same, the benefits expected and the actual experiences were compared. (See Table IX.)

TABLE IX

\section{PROJECT MAIN: WHAT YOUTH INITIALLY EXPECTED} AND LATER EXPERIENCED $(\mathrm{N}=16)$

\begin{tabular}{||l|c|c|}
\hline & Initial Expectations & Later Experiences \\
\hline $\begin{array}{l}\text { Knowledge about gerontology, experience } \\
\text { with the elderly }\end{array}$ & $31 \%$ & $37 \%$ \\
\hline Relating better with other people & 12 & 43 \\
\hline Work experience & 12 & 12 \\
\hline Knowledge about health & 6 & 0 \\
\hline Knowledge about budgeting & 6 & 0 \\
\hline Help toward carecr & 6 & 0 \\
\hline Experience shopping & 6 & 0 \\
\hline Knowledge about nutrition & 6 & 43 \\
\hline $\begin{array}{l}\text { Active participation, responsibility, } \\
\text { dependability, a challenge }\end{array}$ & 6 & 37 \\
\hline Communication skills & 0 & 43 \\
\hline Group process & 0 & 6 \\
\hline Time management & 0 & 6 \\
\hline
\end{tabular}

Data drawn from applications for jobs, sclf-evaluations and evaluations by coordinators 1984 to 1987 . Selection of documents based on availability. Youth giving initial expectations not always the same as those citing later experiences. 
Inspection of Table IX suggests that the Project MAIN experience had been better than the youth had expected. Seven out of 16 said they had learned how to relate with other people. Six out of 16 had been exposed to situations calling for active participation, responsibility, and dependability, and 6 out of 16 had improved their communication skills. Improvements in these three areas make them more acceptable as future employees.

In the health care area, 6 out of 16 had an increased knowledge of gerontology, and had acquired practical knowledge in caring for the elderly. Seven out of 16 had acquired knowledge about nutrition. This would make them more valuable as care givers, especially for the elderly.

\section{Community Evaluation}

A university, a high school, a senior service agency, and grocery stores had helped plan the project. They had been involved and interested in the progress of Project MAIN and their evaluations w'ere important.

Community opinion was an important factor in the support of Project MAIN. Personnel from a senior service agency, a high school, and a store where the clients shopped were interviewed. Several of the parents of the participating youth also were asked for their evaluations of the effects of working for Project MAIN on their children.

\section{$\underline{\text { Senior Service Center }}$}

The senior service center was closely associated with the project. They provided space and telephone service, and at times one of the staff taught a class. They also were the principal source of referrals of elderly clients.

Evaluation by the staff members was generally favorable. The director of the center stated that when elderly persons needed shopping service it was helpful when the same person shopped for the same client as was done by Project MAIN. 
The volunteer coordinator said that it freed up time in terms of volunteers and provided linkage between older and younger people.

Negative evaluation occurred when the elderly clients phoned in to the case managers about broken appointments. This placed an added burden on the case mangers.

The director:

When an elderly person needs shopping, they are probably going to need that continually.... They really need a dependable way of having their shopping done for them. The elderly have really enjoyed the contact.... Some of them have developed a real close relationship above the shopping that has been real stimulating for the elderly and educational for the young people....I think it is great to see youth taking real responsibility and working with some very difficult people.

Volunteer coordinator:

It frees up time in terms of volunteers....It provides a linkage between older and younger people... and it seems to be very successful in that respect....I think this program has the opportunity of fostering good work habits and skills that they can take with them into any work experience.

Case manager:

There are a lot of people home bound. Project MAIN is able to offer more shopping service than we can. I think they have become more aware of what a social service agency does. A lot of them haven't had contact with an agency like ours and they get a better understanding of the day to day working of our agency.... One of the things that Project MAIN has done is to free up case managers to do the monitoring of the clients while the young people do the direct service....It sounds like the Project MAIN folks have really developed good relationships with the people they shop for. I think many times the shopper is one of a very few visitors the elderly person may have in a week. Just that contact with a younger person who provides a different outlook from what the elderly person is used to is a good service.

\section{High School}

Two secretaries gave positive evaluations. One said that the youth were concerned about the people they shopped for, and had a special interest in the rights of the elderly. She had noticed their growing feeling of responsibility for their elderly clients. 
A teacher also spoke of the growing sense of responsibility, and she had noticed a sense of pride that came out of working at something useful.

The principal made his assessment from what the teachers and counselors said, and all their statements had been positive.

Secretary:

They are concerned about the people they are working with. They get real attached to them....They are concerned about the rights of the elderly....I have seen kids who were real 'flakes' become real responsible when it comes to taking care of senior citizens. (Schindler, 1986)

Secretary:

They have a sense of pride, a pride in working at something useful.... They are more concerned with making it better while people are alive than in death itself. (Schindler, 1986)

Teacher:

It has been a revelation to me. Some kids who have been with me have had a shaky experience at one time, but I notice how they pick up on the responsibility quotient....I think they feel better about themselves. It is such an important contribution. (Schindler, 1987)

Principal:

I've had limited contact on a one-to-one basis with the students. However, from the comments of my teachers and counselors, I'd say the effects were positive. (Schindler, 1987)

Store Managers. The two who were interviewed considered the youth to be competent shoppers, performing a valuable service.

After a few weeks' experience the youth were able to find required items with little clerk assistance....Competent shoppers; a valuable service. (Schindler, 1987)

Parents of the Participating Youth. The parents of seven youth were interviewed. Five were single parents. Their assessments of the effects of Project MAIN on the youth all were positive. Five had observed a growth in maturity and two termed it a very marked increase. Other comments were: "more realistic about money," "more self- 
confidence," "new ideas about career choices," "sense of responsibility," and "commitment to another person." All parents agreed that working for Project MAIN had been a valuable experience for the young person. (Schindler, 1987)

\section{Reports to Portland Youth Advocates}

Project MAIN submitted reports to Portland Youth Advocates on a quarterly and annual basis. The quarterly and annual reports for 1984 to the first quarter of 1987 are summarized in Table X.

TABLE X

PROJECT MAIN: OUTPUT AND IMPACT $1984-87$

\begin{tabular}{||c|c|c|c|c|c|c|c||}
\hline Year & $\begin{array}{c}\text { Coordinator } \\
\text { Hours }\end{array}$ & $\begin{array}{c}\text { Number of } \\
\text { MAIN } \\
\text { Assistants }\end{array}$ & $\begin{array}{c}\text { Mobile } \\
\text { Assistant } \\
\text { Hours }\end{array}$ & $\begin{array}{c}\text { Work-Study } \\
\text { Student } \\
\text { Hours }\end{array}$ & $\begin{array}{c}\text { Volunteer } \\
\text { Hours }\end{array}$ & $\begin{array}{c}\text { Number of } \\
\text { Clients } \\
\text { Served }\end{array}$ & $\begin{array}{c}\text { Number of } \\
\text { Shopping } \\
\text { Trips/Escorts }\end{array}$ \\
\hline $1984^{*}$ & 880 & 9 & 5,030 & 1,020 & 139 & 238 & 1,560 \\
\hline $1985^{* *}$ & 800 & 9 & 2,030 & - & 74 & 612 & 1,728 \\
\hline $1986^{* * *}$ & 1,045 & 6 & 3,270 & 40 & 145 & 532 & 1,368 \\
\hline $\begin{array}{l}1987 \\
(1 \text { st Qtr. })\end{array}$ & 223 & 7 & 649 & - & - & 144 & 327 \\
\hline
\end{tabular}

* Annual Report, 1984. Portland Youth Advocates. Portland, Oregon.

** Annual Report, 1985. Portland Youth Advocates. Portland, Oregon.

*** Annual Report, 1986. Portland Youth Advocates. Portland, Oregon.

The number of clients served each year was difficult to gauge. Some of the biweekly time sheets counted each sopping trip as representing service to a different client although each client had a shopper get groceries from one to four times a month. The average number of shopping/escort trips per shopper per month was similar. (See Table XI.) 
TABLE XI

AVERAGE NUMBER OF TRIPS PER SHOPPER PER MONTH

\begin{tabular}{|c|c|}
\hline & Number of Trips \\
\hline 1984 & 14.4 \\
\hline 1985 & 16.0 \\
\hline 1986 & 19.0 \\
\hline $1987^{*}$ & 15.6 \\
\hline
\end{tabular}

* First Quarter only.

The number of youth shopping fluctuated between six and nine at any one time.

They worked part-time over a twelve month period of time. The average number of hours worked each month by each shopper fluctuated as can be seen in Table XII.

TABLE XII

AVERAGE HOURS WORKED BY SHOPPERS EACH MONTH

\begin{tabular}{|c|c|}
\hline Ycar & Hours \\
\hline 1984 & 46.6 \\
\hline 1985 & 18.0 \\
\hline 1986 & 45.4 \\
\hline $1987^{*}$ & 30.8 \\
\hline
\end{tabular}

* First Quarter only.

In 1985, each shopper averaged less work time each week in spite of the fact that the number of shopping trips was greater than for the other years. The total average time worked each month by one or more coordinators did not show as much fluctuation. (See Table XIII.)

TABLE XIII

AVERAGE HOURS WORKED BY COORDINATORS EACH MONTH

\begin{tabular}{|c|c|}
\hline Year & Hours \\
\hline 1984 & 73.0 \\
\hline 1985 & 67.0 \\
\hline 1986 & 87.0 \\
\hline $1987^{*}$ & 74.0 \\
\hline
\end{tabular}

* First Quarter only. 
However, the average time per shopping trip varied especially for 1985 . An average of two hours per weck was assigned to meetings. After subtracting eight hours per month from the total number of hours worked each month by each shopper, the average time for each shopping trip could be calculated. (See Table XIV.)

TABLE XIV

AVERAGE TIME PER SHOPPING TRIP

\begin{tabular}{|c|c|}
\hline Year & Hours \\
\hline 1984 & 2.7 \\
\hline 1985 & 0.6 \\
\hline 1986 & 2.0 \\
\hline $1987^{*}$ & 1.5 \\
\hline
\end{tabular}

* First Quarter only.

Data for Tables XI, XIII, and XIV were drawn from bi-weekly time sheets submitted by Project MAIN shopping assistants. The first full year of the demonstration phase of Project MAIN was 1984. The total number of hours the nine shopping assistants worked was 5,030 (Table X). The total number of shopping trips was 1,560, and the toal number of clients served was 238. In the first year of operation, attention to, and interest in, continuing education was at a peak (Appendix B).

In 1985, the shopping assistants worked only 2,050 hours, less than half the number worked in 1984 . The number of trips was 1,728 compated with 1,560 the previous year. The number of clients was 612 compared with 238 in 1984, although the number for 1985 was questioned because there appeared to be no consistent way of estimating the number of clients (Table X). The average number of hours per month that each shopper worked in 1985 was 18. This number is questionable, as it is not comparable with the times of 46 and 45.4 hours estimated for 1984 and 1986. 
In 1986 , the number of shopping assistants was reduced to 6 (Table X). The total number of hours worked was 3,270,61\% higher than the 2,030 hours worked in 1985. The number of shopping trips in 1986 was $1,368,79 \%$ of the number of trips reported in 1985. However, the average number of trips per shopper each month was 19 , the highest number in the three years of operation. This may have been a factor in the shopping assistants' reports of feeling overwhelmed and tired (Appendix B).

The differences in time spent for a shopping trip could in part be due to time spent in friendly visiting. The goals for the elderly included reducing social isolation and decreasing age segregation. Friendly visiting was one way to accomplish this.

\section{Staff Meetings}

Staff meetings were held weekly and a content analysis was made of the minutes. The content was tabulated under four categories: excerpts related to clients; those related to the participating youth; those related to the community; and those related to Project MAIN. The frequency of these excerpts were compared over time for the years 1984 to 1987. See Table XV.

\section{TABLE XV}

FREQUENCY OF EXCERPTS RELATING TO CLIENTS, YOUTH, COMMUNITY, AND PROJECT MAIN

\begin{tabular}{||c|c|c|c|c||}
\hline & Clients & Youth & Community & MAIN \\
\hline 1984 & 6 & 2 & 3 & 1 \\
\hline 1985 & 4 & 2 & 1 & 6 \\
\hline 1986 & 3 & 14 & 2 & 8 \\
\hline $1987^{*}$ & 0 & 0 & 0 & 4 \\
\hline
\end{tabular}

*First quarter only 
Exclusive of 1987 , the number of excerpts relating to clients decreased by $50 \%$ between 1984 and 1986. In the same period of time excerpts relating to the youth increased by $700 \%$ and those relating to the functioning of Project MAIN by $800 \%$. Their focus of attention was on themselves and their problems.

In 1984, the coordinators had been trained at the time of the pilot project which gave 80 hours of training. By 1986, the coordinator was a shopper who had been trained by the first coordinator. Pre-shopping training time had been reduced to six hours. One hour of education per week was planned, but attendance was poor. The requirement of continuing education in order to continue employment was not enforced. The shoppers were less well prepared and less sensitive to the needs of the elderly.

During 1986, the participating youth had complaints of low energy, feeling overloaded, and reported an increasing number of broken appointments with their clients. This continued until Project MAIN was terminated in March, 1987.

\section{Summary}

Project MAIN assisted the frail elderly with shopping, helping them to live fuller and more independent lives (Blake, 1985a). In addition, the project to some degree reduced the burden placed on social service agencies as increasing numbers of frail elderly needed this assistance.

Project MAIN addressed the need of urban youth for part-time employment. This let the youth remain in school and keep their career options open, and gave them the satisfaction of working in a meaningful job that was making a contribution to the community.

The program brought together youth and the elderly in a mutually supportive and caring way. This helped to reduce social isolation and age segregation frequently encountered in the elderly. 
Planning for Project MAIN was carefully done and the planners included an urban university, a high school, a neighborhood grocery store, and a local senior service agency. Something that appeared to be a minor factor was not explored during the preliminary planning. Recruitment of elderly clients was discussed, but determination of the maximum number of clients for a given number of shoppers was not considered. No plan was made for managing requests for service above the number that could be handled by the shoppers.

The community was generous in providing resources for operation of Project MAIN. However, financial support was provided by private foundations and this proved to be an area of great concern. Adequate funding was a problem from the beginning and became greater with the passage of time. Foundations that were willing to give to a new project were less willing to support an ongoing program. It was hoped that when the program had proved itself, some agency or group would take over its management, but this did not happen.

At the beginning of the demonstration phase, there was not sufficient money to employ a director and an instructor. The functions of director and instructor might have been combined, but that would have been at the expense of some of the youth who provided the shopping service. For a short time, a graduate student coordinated the program, and later one of the more experienced youth assumed that position. As long as the coordinator was one of the youth trained in the original pilot project, the program functioned satisfactorily, and service to the elderly remained good.

Later when the coordinator was a youth who had not been trained in the pilot project, difficulties emerged. Pre-shopping training for newly recruited youth was reduced to six hours. Weekly educational sessions were reduced by the needs of the project itself. Insufficient time remained for ongoing training. The youth began to 
concentrate on their own problems and broken shopping appointments began to increase (see Appendix B).

The number of frail elderly asking for shopping service continued to increase, but there was no money to hire additional youth. This placed a heavier burden on youth who already were feeling overloaded.

The youth stated that they felt they needed more training, yet they frequently were absent from weekly educational meetings. One of the criteria for continued employment was ongoing training, but this policy was not enforced.

Early planning was needed to determine if the project could afford to eliminate paid leadership positions. A determination also was needed to limit the maximum number of clients who could be serviced by a set number of youth.

Analysis of the pilot project indicated that Project MAIN could provide a dependable shopping service for the frail elderly. As the demonstration phase of the project continued, some difficulties appeared, but $74 \%$ of the clients surveyed responded with favorable comments. (See Appendix D) The factors contributing to difficulties have been identified and analyzed and this information can be used in planning future programs. 


\section{CHAPTER VIII}

\section{CONCLUSIONS}

\section{INTRODUCTION}

This study focused on two urban populations. The frail elderly were attempting to maintain their independence and remain in their own homes in the community. One of their needs was a dependable supply of food, a necessity for independent living. Secondary needs of the elderly were to decrease social isolation and age segregation. Youth at risk of dropping out of school had special needs also. They needed an increase of part-time jobs that would allow them to continue in school and keep their career options open. In addition, earnings from the jobs would assist the youth in their quest for independence.

Project MAIN was planned to meet the needs of both these groups. It trained and employed youth part-time to provide regular and dependable shopping service to the frail elderly. For the youth, this was a meaningful job which made a needed contribution to the community. Moreover, the training and the experience of the job facilitated the transition from school to the work place.

This study attempted to answer two questions:

1) Did Project MAIN meet the needs of the frail elderly:
a. for a dependable supply of food?
b. to maintain independence and autonomy?
c. to decrease social isolation and age segregation? 
2) Did Project MAIN meet the needs of at-risk youth:
a. to achieve independence and autonomy?
b. to facilitate transition from school to the work place?
c. to earn money to expand independence?

In interviews with 22 of the elderly clients who discussed the shopping service as a means of getting a dependable supply of groceries, 20 rated the service as satisfactory. (See Appendix F.) This in itself increased the feelings of independence and autonomy in the elderly, and this was reflected in their responses in the interviews.

A decrease in the social isolation of the elderly was part of the plan for the shopping service, and this was accomplished by regular visits by the young shoppers. One client said that the compaionship was the best aspect of the service.

A decrease in age segregation was another goal for Project MAIN. But of 50 interviews with the elderly clients, there were 40 comments about youth (see Appendix F). Seven spoke unfavorably about their hair and clothing. One elderly person thought colored hair was "cute" while another dislike it. Fourteen of the elderly spoke well of the youths' openness, consideration, caring and thoughtfulness, and of their intelligence, confidence, and willingness to work hard. However, there were negative comments about some youth being wild and disrespectful, and the elderly disliked the drug culture and the music. One client said she had to overcome her feelings about the differences, but that she liked youth. With frequent contacts with youth over an extended time, the elderly clients were being exposed to a different point of view, and both youth and the elderly were learning to live with the differences.

Project MAIN met the needs of urban youth for jobs that provided them with an income. This in itself helped them move toward independence and autonomy. 
Table IX documented ways in which Project MAIN provided learning experiences that would facilitate the transition of young people from school to the work place. They learned how to relate better with other people, and had improved their communication skills. They experienced situations that called for active participation, responsibility, and dependability. In their close association with the case managers of their elderly clients, they had participated in cooperatively working with adults in an adult work environment.

\section{Impact of Project MAIN}

Project MAIN provided a new agency to help meet the needs of the frail elderly for a regular and dependable supply of groceries. This relieved case managers of the time-consuming task of shopping. It pointed out the need for this type of agency in a neighborhood with a large number of frail elderly people. It prepared the neighborhood for another new agency that would shop for a larger number of clients.

Project MAIN also demonstrated that well prepared youth were capable of dependable service to the elderly, and could perform many of the tasks in operating the program. It was found that training of participating youth and leadership of the program are performed better by more mature and knowledgeable adults, but other tasks are well within the ability of the youth.

\section{Outcomes}

The outcome of the project was measured by the level of satisfaction of youth and the elderly.

The pilot project trained the youth intensively for four weeks and provided strong academic support and careful supervision when they moved into the phase of supplying a shopping service to the elderly. The participating youth received minimum wage and had the satisfaction of taking an active part in a worthwhile program. The elderly expressed their satisfaction with the service, especially its availability and dependability. 
The demonstration phase of the project presented many new problems. The time the youth could commit to working for Project MAIN was reduced by the school schedule. Time for training both before youth started shopping and later as a continuing education program was limited and became difficult to schedule. As experienced shoppers left the project and new one were recruited, their training placed demands on the time of those who functioned as instructors. Funds for continuing the project became more difficult to find. Money that was needed for a coordinator and trainer was diverted to the salaries of youth who were needed for an increasing demand for the shopping service.

As this continued, complaints from the elderly increased. Generally, these complaints focused on decreasing dependability although 37 of 50 elderly clients who were interviewed found aspects of the service good. The youth showed their dissatisfaction in other ways. Increasingly in staff meetings, the youth spoke of not feeling well, of being tired, and of feeling burnt out. They also spoke of a need for more training and more interaction within their group to increase a feeling of group solidarity.

The need for a shopping service continued after Project MAIN was terminated. Senior service agencies were able to provide this service to some of the housebound elderly. One of the branches of a supermarket chain has one morning a week designated for elderly shopping. A special bus makes a trip to bring shoppers to the store, and later returns them to their homes. Extra staff are on hand in the store to assist the elderly.

Another supermarket chain offers shopping by phone. An extensive catalogue makes choices of items easier. The groceries are delivered within 24 hours. There is a charge for this service which is a hurdle to those living at or below the poverty line. Some have difficulty in making out a shopping list of nutritious foods. 
These services which are meeting the shopping needs of the frail elderly will, after the discontinuance of Project MAIN, continue to reach only a small part of the frail or disabled elderly. Additional ways of meeting these needs are called for.

\section{RECOMMENDATIONS}

\section{Funding}

From the experience of the demonstration phase of the project, it became obvious that adequate funding was essential not only for the maintenance of the shopping service, but also to maintain good service. The experience suggests that without adequate training and supervision, quality performance was in jeopardy. Decisions reed to be made at the planning stage regarding priorities. Elimination of director and instructor in order to hire more shoppers may not be in the best interest of the project.

\section{Maximum Number of Elderly Clients}

This needs to be determined in the planning stage. For a specified number of shoppers, the maximum number of elderly clients needs to be set. If this number is exceeded, it results in pressure on the shoppers to take time from necessary meetings and training sessions in order to shop for their clients.

\section{Training of Youth}

The youth trained for the pilot project performed well and there was an absence of complaints from the elderly clients. The eighty hours of training for this group of shoppers may be more than necessary in order to prepare a youth to shop. A careful analysis of the curriculum could decide what is essential for youth to know before they begin the task of shopping for an elderly client. Material not covered in this pre-shopping preparatory period then could become the basis for weekly educational periods. These topics can be varied and enriched so there is not repetition for those who have been in 
Project MAIN for several months. Youth need to be active participants in these presentations and it is important that they keep the instructor informed on information that they find they need.

\section{Mandatory Continuing Training}

Ongoing education is one of the criteria for employment in Project MAIN. This needs to be strictly enforced. Attendance at training sessions should be mandatory with sanctions enforced if this is not complied with. One of the complaints of the youth was that Project MAIN was not strict enough in enforcing its policies.

\section{Youth Participating in Instruction}

Some of the youth may be interested in teaching and this should be encouraged. However, the control of the educational sessions should remain with a mature, experienced instructor.

\section{Supervision of Shopping Service}

The director or coordinator needs to be in close contact with the activities of the shoppers. If a new client asks for service, the coordinator needs to call that client within twenty-four hours to make sure that the client has received shopping service. That should remove the possibility of the new client having to wait two or three weeks to receive groceries. It should also decrease the number of calls to the case managers from clients in need of groceries.

Close contact needs to be maintained between shoppers and coordinator, and this has been done through each youth phoning in on a daily basis. This also should be mandatory with sanctions enforced if not complied with. 
Distribution of clients among shoppers needs to be maintained in order to equalize work loads. A bulletin board could be kept up-to-date with the names of clients under the name of each youth, with day and time of shopping. This would facilitate assignment of new clients equitably.

There will be times when a shopper will be unable to meet his or her commitment to shop for a client. It will be necessary for another shopper to contact the client and arrange for the shopping. When possible, these arrangement can be made by the shoppers themselves, and the coordinator notified.

\section{Recruitment of Youth}

The principal of the high school said that he believed that the participating students were self-selected regarding potential for commitment, responsibility, and trustworthiness. If this process of self-selection continues, it appears that suitable youth will be interested in this type of project.

Training new recruits one at a time takes a lot of the instructor's time. This problem could be dealt with more efficiently if two or more new youth were trained at the same time. This could be at specified times, perhaps related to the beginning or end of school terms. When hired by Project MAIN, each youth would sign an agreement containing the statement that he or she would work for three months. At the end of that time, they would again sign up for three months. This would serve to stabilize the size of the group of shoppers.

The pilot phase of Project MAIN has proved that this is a viable concept for planning a way for meeting a community need. From the experience of the demonstration phase, it becomes obvious that adequate funding is essential not only for the maintenance of the shopping service but also to maintain good service. Without adequate training and supervision, quality performance is in jeopardy. Carefully considered decisions need to be made at the planning stage regarding priorities. 
Replication of the Project

It would be of interes $i$ if another project with these areas of difficulty remedied was carried out and the outcomes compared with the pilot project. Most of the elderly clients in Project MAIN were white, English speaking citizens. It would be of interest to replicate this project with other ethnic groups to explore the modifications called for by people of different cultures.

\section{SUMMARY}

Project MAIN was planned on a sound theoretical basis by the joint efforts of a university, a high school, grocer stores, and social service agencies. The pilot project showed that it could perform its task of providing a dependable shopping service for the frail elderly and provide jobs for at-risk youth.

Problems that arose in its operations were identified and ways of correcting them suggested. The project was a viable way of meeting a community need, and replications with different groups and with modifications would provide important information about optimum ways of meeting the needs of urban frail elderly and at-risk youth.

This concept of organizing to meet a community need for a shopping service may be called on for another group desperately in need of help. With the increase in numbers of HIV infected individuals, it can be foreseen that there will be an increasing number of people who are unable to do their own grocery shopping. With a growing need for institutional care for those in later stages of AIDS, a heavy burden will be place on community facilities. A dependable and regular shopping service could prolong the time that an infected person could remain in the community. This is a problem that promises to have policy implications. Project MAIN offers a viable concept for meeting a community need that would postpone the need for expensive institutional care. 
Evaluating Project MAIN by the Matrix

The matrix (p. 55) that was used to evaluate five intergenerational programs was also utilized in evaluating Project MAIN in an attempt to determine which areas needed improvement.

Defined need - Good.

Resources - Inadequate funding. No long term, ongoing commitment.

Planning - None made for too many demands for service.

Goals - Good.

Recruitment of Youths - Timing of admission of new shoppers to conserve time needed for training.

Training - Well prepared shoppers for pilot project. Training decreased during demonstration project.

Evaluation - Ongoing.

Impact - A new agency to meet community need.

Outcome - Feasibility of using well prepared youth established. Lack of longterm funding resulted in a group of frail elderly, who had become dependent on Project MAIN, deprived of a shopping service.

On careful analysis, it appears that the inner deterioration of Project MAIN was a result of outside influence in the form of lack of funding.

\section{What Would Work}

Some outstanding problems are highly visible. Ongoing, adequate funding is an overriding need and underlies other problems. Until this need for funds is remedied, a project such as Project MAIN cannot continue successfully.

An increasing demand for the shopping service suggests success for the program, but can lead to deterioration of the service if plans for referral are not formulated, or sufficient money provided to hire additional shoppers. 
The success of the pilot project is a function of well prepared youth. Sufficient money is required for training the youth, and enough shoppers are needed so all shoppers have time available for classes.

\section{What can be Learned from Project Main}

Risk taking. In recruiting youth, a primary criteria was an interest in the elderly and their unmet needs. The youth did not have to meet academic standards, nor was there concern about exposing the elderly to a wide range of young people.

\section{Need to Maintain and Increase a Sensitivity to the Elderly}

In the pilot phase, the intense training promoted this interest and sensitivity. In the demonstration project, with decreased time for training, interest and sensitivity noticeably decreased.

\section{Youths' Desire for Increased Structure}

Youth expressed a need for stricter rules. On analysis, this included better communication among shoppers, coordinators, and other staff, resulting in closer supervision of the operation of the shopping service. It also included enforcement of rules regarding mandatory attendance at staff meetings and training sessions.

\section{Best Aspects of Project MAIN}

Project MAIN was successful in meeting a community need for a shopping service for the home bound elderly. It demonstrated that well-trained youth could be reliable and dependable workers. A second aspect was the sense of ownership that the youth had in the program.

Pitfalls

Project MAIN demonstrated the result of inadequate and ongoing funding which contributed to deterioration of the inner strength of the program. 


\section{REFERENCES}

Allen, Margery. "Channel-One: An Intergenerational Program at Work," Children Today, May June. 1986. pp. 32-34.

Altman, Irwin. "Reciprocity of Interpersonal Exchanges," Journal of Theory of Social Behavior, 3:2. 1973. pp. 247-261.

Aronstein, Lawrence W. and Edward G. Olsen. Action Learning. Washington, D.C.: Association for Supervision and Curriculum Development, 1974.

Bachrach, Christine A. "Childlessness and Social Isolation Among the Elderly," Journal of Marriage and the Family, 1980. pp. 627-636.

Barranti, Chrystal C. Ramirez. "The Grandparent/Grandchild Relationship: Family Resource in an Era of Voluntary Bonds," Family Relations, 34. 1985. pp. 343352.

Baum, Martha, Sally Newman, and Barbara Shore. "Learning About Aging Through Intergenerational Experiences," Gerontology and Geriatric Education. Summer, 1986. pp. 214.

Bengtson, Vern L. "Research Perspectives on Intergenerational Interaction." Quoted in Pauline K. Ragan (ed.), Aging Parents. Chapter 4. Los Angeles, CA: , 1979. pp. 37-57

Blake, Gerald F. “Mobile Assistants in Nutrition," Portland, OR. 1985.

"Collaboration for School Improvement and Community Service," Educational Leadership, 1986a.

"Project MAIN: Classwork in the Community Benefits Senior Citizens," Children Today, 1986b. pp. 31-34.

Blake, Gerald F., Jane Goldstein-Pullman, and Robin S. Stephens. "Action Planning and Youth Employment: An Examination of Strategies Used to Establish an Innovative Inter-Age Employment Prototype." Prepared for presentation at the Society for the Study of Social Problems, 32nd Annual Meeting. Detroit, MI: 1983.

Blau, Peter M. "Exchange and Power in Social Life." Quoted in James J. Dowd. "Aging as Exchange: A Preface to Theory," Journal of Gerontology, 1975. pp. 584-594.

Borus, Michael E. (ed.). Youth and the Labor Market. Kalamazoo, MI: Upjohn Institute for Employment Research, 1984. 
Braithewaite, Valerie, Diane Gibson, and Jacqueline Holman. "Age Stereotyping: Are We Oversimplifying the Phenomenon?" International Journal of Aging and Human Development, 22 (4), 1985. pp. 315-325.

Burgess, Robert L. and Ted L. Huston. Social Exchange in Developing Relationships. New York, NY: Academic Press, 1979.

Cain, L. D. "Population Aging and Family Life." In G. M. Gutman (ed.) Canada's Changing Age Structure: Implications for the Future. Burnaby, B.C.: Simon Fraser University Publications, 1982.

Chapman, Nancy J. and Margaret B. Neal. "The Effects of Intergenerational Experiences on Adolescents and Older Adults." Gerontologist, 30:6. 1990.

Doka, Kenneth J. "Adolescent Attitudes and Beliefs Toward Aging and the Elderly," International Journal of Aging and Human Development, 22:3. 1984. pp. 173187.

Dowd, James J. "Aging as Exchange: A Preface to Theory," Journal of Gerontology, 30:5. 1975. pp. 584-594.

Dowd, J. and R. LaRossa. "Primary Group Contact and Elderly Morale: An Exchange/ Power Analysis," Sociology and Social Research, 66. 1982. pp. 184-197.

Erickson, Erik H. Identity: Youth and Crisis. New York, NY: W. W. Norton and Co., Inc., 1968.

Eustis, Nancy N., Jay N. Greenberg, and Sharon K. Patten. Long-Term Care for Older Persons: A Policy Perspective. Monterey, CA: Brooks/Cole Publishing Company. 1984.

Fanelli, Marie T. and Marilyn M. Abernethy. "A Nutritional Questionnaire for Older Adults." The Gerontologist, 26:2, 1986. pp. 192-197.

Foa, Edna P. and Uriel G. Foa. Chapter 4. "Resource Theory: Interpersonal Behavior as Exchange." Cited in Kenneth J. Gergen, Martin S. Greenberg, and Richard H. Willis, eds. Social Exchange: Advances in Theory aild Research. New York, NY: Fienum Press. 1980.

Freeman, Richard B. and David A. Wise. The Youth Labor Market Problem: It's Nature, Causes, and Consequences. Chicago, IL: University of Chicago Press, 1982.

Galvin, Siobhan M. and Sally Newman. "Youth in Service to Elders: Bring Old and Young Together," Generations Together. University of Pittsburgh. 1984.

Greenberger, Ellen and Laurence Steinberg. When Teenagers Work. New York, NY: Basic Books, Inc., 1986.

Grubb, W. Norton. Preparing Youth for Work: The Dilemmas of Education and Training Programs. Austin, TX: University of Texas, 1985. 
Lee, Gary R. and Eugene Ellithorpe. "Intergenerational Exchange and Subjective WellBeing Among the Elderly," Journal of Marriage and the Family. 1982. pp. 217224.

Levin, Martin A. and Barbara Ferman. The Political Hand: Policy Implementation and Youth Employment Programs, Permagon Government and Politics Series. New York, NY: Pergamon Press. 1985.

Lewin-Epstein, Noah. Youth Employment During High School. Chicago, IL: National Opinion Research Center, 1981.

Ludman, Elaine Kris and Jacqueline M. Newman. "Frail Elderly: Assessment of Nutrition Needs." The Gerontologist, 26:2, 1986. pp. 198-202.

Madje, Judy. Door to Door. Portland, OR: Perconal communication, 1992.

Maslow, Abrahani. "Deticiency Motivation and Growth Motivation." In James C. Coleman, Personality Dynamics and Effective Behavior. Chicago, IL: Scott, Foresman and Company, 1960. pp. 475-485.

"Hierarchy of Needs." In Raymond Corsini (ed.) Current Psychotherapies. Iiasca, IL: F. E. Peacock Publishers, 1972. pp. 132, 294.

Neugarten, B. L. "Policy for the 1980's: Age or Need Entitlement." In Age or Need? Public Policies for Older People. Beverly Hills, CA: Sage Publications, 1982.

Newman, Sally. Rationale for Linking the Generations. Presented at NCOA MiniConference, University of Georgia, Athens, GA. 1980.

"Intergenerational Programs: Their Role in American Society," Generations Together. University of Pittsburgh. 1983.

Organization for Economic Cooperation and Development. The Nature of Youth Employment. Paris, France, 1984.

Osterman, Paul. The Job Market for Adolescents. Boston, MA: Boston University. 1985.

Patton, Michael Q. Qualitative Evaluation Methods. Beverly Hills: Sage Publications, 1988.

Pearl, Arthur and Frank Riessman. New Careers for the Poor. New York, NY: Free Press, 1965.

Portland/Multnomah Commission on Aging. Good Nutrition: A Lifetime Challenge. Portland, OR. 1985.

Portland Youth Advocates. New Careers for Youth: A Program for the Eighties. Portland, OR. 1982. Mobile Assistant in Nutrition. Portland, OR. 1985. 
Annual Report. Portland, OR. 1984 - 1987.

Pratton, Jerry and Loyde W. Hales. "The Effects of Active Participation on Student Learning," Joumal of Educational Research, 794:4. 1986. pp. 210-215.

President's Science Advisory Committee, Office of Science and Technology. Youth: Transition to Adulthood. Executive Office of the President. 1973.

Pullman, Jane. Portland Area Youth Survey. Portland, OR: Portland Youth Advocates, 1982.

Ragan, Pauline K. and Vern L. Bengtson (eds.) Chapter 4. “Aging Parent." Research Perspectives on Intergenerational Interactions. Los Angeles, CA: University of Southern California Press. 1979.

Rosenwoike, Ira. The Extreme Aged in America: A Portrait of an Expanding Population. Westport, CT: Greenwood Press, 1985.

Schindler, Doris. Personal Interviews with Project MAIN Participants. 19??

Shanas, Ethel. "Older People and Their Families: The New Pioneers," Journal of Marriage and the Family. 1980. pp. 9-15.

Soldo, B. J. “America's Elderly in the 1980's," Population Bulletin, 35 (4), 1980. pp. 147.

Steinberg, Lawrence D. "Jumping Off the Work Experience Bandwagon," Journal of Youth and Adolescence, 11. 1982. pp. 183-206.

Stern, David. "School-Based Enterprise and the Quality of Work Experience," Youth and Society, 15:4. 1984. pp. 401-427.

Stern, David and Yoshifuma Nagata. Why is Work Experience Good for High School Students? Berkeley, CA: University of California, 1985.

Stoller, E. and L. Earl. "Help with Activities of Everyday Living: Sources of Support for the Noninstitutionalized Elderly." The Gerontologist, 23. 1982. pp. 64-70

Strauss, Anselm. Qualitative Analysis for Social Scientists. Cambridge, MA: Cambridge University Press, 1987.

Strauss Anselm and Juliet Corbin. Basics of Qualitative Research. Newbury Park, CA: Sage Publications, 1990.

Streib, Gordon F. and Rubye Wilkerson Beck. “Older Families a Decade Later," Journal of Marriage and the Family. 1980. pp. 937-956.

Tice, Carol H. "Intergenerational Initiatives: Past, Present and Future," Children Today. September-October. 1985. p. 9.

"Developing Friendships Between Teens and Adults," Children Today. September-October. 1985. pp. 20-22. 
Treas, Judith and Vern L. Bengtson. "The Demography of Mid- and Late-Life Transitions." In Felix M. Berardo, ed., The Annals of the American Academy of Political and Social Science. Beverly Hills, CA: Sage Publications, 1982.

U.S. Department of Commerce, Bureau of the Census. General Characteristics of the Population. Census Tracts in Portland, Oregon, Washington S.M.S.A. Washington, D. C.: Government Printing Office, 1970. pp. 85-86

Current Population Survey. Summary I-40. Table 262-A. Years of School Completed for Persons 15 Years Old and Over by Age, Sex, Race and Spanish Origin. Washington, D. C.: Government Printing Office, 1980.

Current Population Reports. Series P60. No 151. Money Income of Households, Families and Persons in the U.S. Washington, D. C.: Government Printing Office, 1984.

Series P60, No. 152. Characteristics of the Population Below the Poverty Level. Washington, D. C.: Government Printing Office, 1984.

Ventura-Merkel, Catherine and Marc Freedman. "Helping At-Risk Youth Through Intergenerational Programming," Children Today. January-February. 1988. pp. 10-13.

Vogel, Ronald J. and Hans C. Palmer, eds. Long-Term Care. U.S. Department of Health and Human Services. 1983. 
APPENDIX A

GUIDED INTERVIEW: PORTLAND AREA YOUTH 
General Data:

1. Age.

2. General area of residence.

3. Male or female.

4. Race.

5. General living situation (home, foster home, etc.)

6. In school, working, or both.

General or open-ended questions:

1. What are the major problsms facing you as a Portland area young person?

2. What do you see as the major problems facing Portland area youth in general?

3. What would you like to see happen to make the Portland area a better place for youth to be? What is needed?

Possible topic areas to be supplied if needed:

1. Job (\$).

2. Recreation (what to do and where).

3. Societal pressures (family, peers, etc.).

4. School (how is it for you).

5. Are youth treated with respect in the Portland area?

6. Drugs (too many? not enough? peer pressure?).

7. Laws. 
APPENDIX B

EXCERPTS FROM PROJECT MAIN WEEKLY STAFF MEETINGS: $1984-1987$ 
January to December, 1984

Helped clients register to vote.

Prepared brochure on Project MAIN.

Neighborhood festival booth on the aging process.

Slide show on Project MAIN.

Reports on conferences.

Problem clients - the talkative client.

Death of a client.

Two clients hospitalized.

Client robbed - shopper will follow up on this.

Workshop on aging.

Conference at Portland State University.

Facilitator and secretary always to be chosen in advance for the next meeting.

Three new coordinators to replace the one who is leaving.

Need for "clear the air" sessions.

Reminder to check in daily (2).

January to December, 1985

Nutritional teaching of clients.

Recruiting new youth for Project MAIN; criteria for applicants.

Covering for one another; vacations; when a shopper leaves until replacement is trained.

Weekly report by each youth on all clients.

Two youth feel overloaded.

Youth feel need for more structure.

Discussion on networking.

Need to cover for each other. 
Discussion of classes and group discussions.

Decisions to read and discuss articles.

Communication; necessary to report in and out daily for new referrals; otherwise places burden on case managers.

Need for punctuality at classes and meetings (5).

Need to make time to come to meetings.

January to December, 1986

Youth noticed expired elevator permit in apartment; to follow up on this.

Discussion of fire-escape and stairs.

Conducted survey on eating habits of clients.

An ex-client died.

Discussed response to angry, demanding client.

Five shoppers forgetful; feel overloaded, tired, "spacey."

One reported as undependable.

One rescheduled a client when youth was ill.

Three shoppers missed clients.

Three youths reported low energy, dragging all the time; burned out; tired from outside commitments.

One angry and depressed and missing clients.

Coordinator feels overloaded.

Director of senior service agency: “...youth need more training and supervision...a troubleshooter...Project MAIN needs $\$ 1,000$ a month to keep going..."

Project MAIN policies edited and expanded.

Discussion on suicide.

Concern about low attendance at meetings. 
Continuing problem of shoppers not checking in; three did not check in one afternoon.

Continuing problem with one shopper who does not check in.

Youth feel there is not enough contact between each other.

Need more sense of group identity.

Need more training.

Need more social time.

January to March, 1987

Discussion on deterioration of some clients.

Discussion on death and dying.

One youth forgot to shop one day.

One was tired and forgot client.

One was "spaced out" and forgot client.

Two youth agreed to help coordinator with training of new shoppers. 
APPENDIX C

CERTIFICATION OF ACTION LEARNING CREDIT 
Portland Youth Advocates certifies that has completed hours of employment with the Mobile Assistants in Nutrition project. Project M.A.I.N. is a shopping escort and deliver service operated by Portland Youth Advocates that combines action learning and employment for youth ages 14-21. Each Mobile Assistant received twenty-four (24) hours of training in the fields of gerontology, nutrition, and grocery economics, oral communications, and disability awareness. Training is provided by social service and business professionals, and by university faculty and graduate students. The youths are paid $\$ 3.00$ per hour, and work approximately 12 hours per week after school and on weekends.

The Mobile Assistant's job duties include receiving referrals from senior service agencies, elderly and disabled housing managers, and grocery store managers, having frequent telephone and personal contact with senior citizens and the physically disabled, and becoming familiar with the staff and operations of several local grocery stores. The Mobile Assistants are also responsible for reading assigned articles relating to the work of the project and for participating in weekly group discussions about the project and the readings. Project M.A.I.N. stresses group/team participation in the planning and operation of the service.

\section{SUPERVISOR'S COMMENTS:}

Date: 
APPENDIX D

APPLICATION FOR EMPLOYMENT 
NAME:

ADDRESS:

TELEPHONE:

SCHOOL: GRADE:

SOCIAL SECURITY NUMBER:

DO YOU HAVE A WORK PERMIT?

PREVIOUS WORK EXPERIENCE (Employer's name, dates of employment)

SPECIAL INTERESTS (writing, hobbies, clubs or organizations, etc.

REASONS WHY I AM APPLYING FOR THIS JOB

WHAT EXPERIENCE HAVE YOU HAD HELPING ELDERLY OR DISABLED PEOPLE?

HOW DO YOU EXPECT TO BENEFIT FROM WORKING ON PROJECT MAIN?

REFERENCES (list the names and telephone numbers of two references who are unrelated to you) 
APPENDIX E

PROJECT MAIN 1985: ASSESSMENT BY CLIENTS 
Name:

Address:

Telephone No.:

Age:

A. 1. How did you hear about Project MAIN?

2. How long have you had this service?

3. Did you have assistance with shopping before Project MAIN?

4. What problems did you have with shopping?

B. 5. Who helps you with shopping?

6. How often has he/she shopped for you?

7. How was he/she introduced to you?

8. Is he/she friendly?

9. Is he/she formal?

10. Is he/she courteous?

11. Is he/she dependable?

12. Is he/she respectful?

13. Is he/she professional?

14. Is he/she trustworthy?

15. What does he/she do particularly well?

C. 16. In general, how would you assess this service?

17. What is the best aspect of the Project MAIN service? 
18. What is the worst aspect?

19. What suggestions do you have to improve the service?

20 Would you recommend this service to a friend?

D. Young people today are different in dress and behavior from fifty years ago.

21. What changes do you like?

22. What changes bother you? 
APPENDIX F

PROJECT MAIN SURVEY: RESPONSES OF CLIENTS $(\mathrm{N}=50)$ 
1. One shopper dependable and trustworthy; another was not.

2. Lack of respect.

3. Follows instructions meticulously. Best aspect of Project MAIN - my survival. Youth are more independent, become more responsible. This may be positive or negative; may be too heavy a burden. Don't like colored hair, make-up, drugs.

4. Quick with shopping; generally good except when short of time. Best aspect-you get what you want when you want it. Worst aspect - not being able to see what you are getting.

5. Follows instructions. Keeps me from starving; could not live without it. Like their independence, greater knowledge, and interest in world affairs. Don't like colored hair.

6. Best aspect - same person does the shopping.

7. Capable but not to be depended on. Best aspect - do not have to take housekeeper's time to do the shopping.

8. Fast shopper.

9. Dependable. Helped hang drapes.

10. No comments.

11. Helps me make out shopping list; plans ahead. Only way to get food to supplement meals-on-wheels.

12. No comments.

13. Good judgment, considerate, and thoughtful. Colored hair cute.

14. Does well but may be inexperienced in shopping. Changing days for shopping is difficult. Youth a little wild.

15. Not to be depended on. Not always on days decided on. Knows brands, prices, quality. Knows produce. Idea of shopping service good. Best aspect-physical 
assistance, companionship. Changes in youth; want so many things; have so much money to spend.

16. Minor mistakes if not clearly specified. Service wonderful; one of the finest things that ever happened. Only way to get groceries. Youth intelligent. Some lack of respect for old people; don't understand; don't want to be bothered.

17. Never make a big mistake.

18. Finds items wanted. So honest. Have to overcome their differences but like young people. Know fads and changes in these fads.

19. Goes back to store if necessary. Best aspect - weekly service.

20. Needs time to be assured of dependability and trustworthiness. Some are not honest or truthful. Competent shopper. Very helpful.

21. Fills in when friends cannot shop. Don't like music, hair.

22. Does well; fruit and vegetable choices. Available when grandson cannot help. Be sure list is specific. Like their opportunity for more education. Don't like; education not as good; mothers working.

23. A fast shopper. Available. Like - freer, more open. Don't like - the way they dress.

24. Can help plan meals; shops wisely. Good at sharing. A very caring young person. Shopping service a God-send; keeps me in my apartment; otherwise a nursing home. Like their openness. Dislike the drug culture.

25. Trustworthy. Service very good, keep it going. Like their sharpness, confidence. Some are rude and condescending (not Project MAIN youth).

26. Once got wrong kind of tomato sauce. Service available. Many youth friendly. Some disrespectful.

27. Misses items on list. Quick and dependable. Needs better training, especially vegetables. Don't like their clothes and hair.

28. No comments. 
29. No comments.

30. Had a Project MAIN shopper once. Not a good shopper.

31. Always get specified items. Service is A-1. Able to get groceries without having to go out. Youth easy going. Don't like music, drugs.

32. Knows how to save money. Service good; available. Don't like the way youth talk.

33. One shopper was dependable; another was not and changed appointments. Some question about change once. Chooses fruit and vegetables well. One shopper good; another only fair. Like the way youth work hard. Don't like ragged clothing.

34. Good shopping choices. Service good; available when needed. Worst aspect broken appointments. Like youth. They have more freedom, more knowledge. Don't like hair, dress.

35. One shopper efficient, another was not. Best aspect of service - availability. Like in youth their openness. Don't like the way the run around too much.

36. Shopper goes out of her way. Service excellent. Suggest help in putting groceries away.

37. Not always dependable. Appearance needs improvement.

38. One shopper was supposed to come and never showed up. One was trustworthy, another was not. Good shopper. Best aspect - available. Youth seem smarter. Don't like scruffy appearance.

39. Called for shopping service because of medical problem and she needed food for dinner. Shopper not available until 7 p.m.

40. Service good.

41. Dependable service.

42. Excellent shopper. Likes young people.

43. Excellent shopper. Service available. Young people confuse her. 
44. Shopper has good judgment. Service good. Available for heavy and bulky shopping.

45. Undependable and untrustworthy.

46. One shopper did not come as promised. Not businesslike. Untrustworthy.

47. Undependable. Don't know if she could trust shopper. Best aspect - accessible.

48. Service good.

49. One shopper undependable; the other two very dependable. Does well; knows store well. Service good; available at given times. Worst aspect - broken appointments and making the initial appointment.

50 Good shopper. Service good. 